\title{
LA ORIENTACIÓN SEXUAL ANTE EL TRIBUNAL EUROPEO \\ DE DERECHOS HUMANOS
}

\author{
ESTELA GILBAJA CABRERO
}


SUMARIO

1. INTRODUCCIÓN. 2. ORIENTACIÓN SEXUAL Y DERECHO PENAL:

2.1. Asuntos relativos a la prohibición de las relaciones homosexuales. 2.2. Asuntos relativos a la edad de consentimiento para las relaciones sexuales. 3. ORIENTACIÓN SEXUAL Y VIDA FAMILIAR: 3.1. Matrimonio y otras formas de reconocimiento jurídico de las relaciones estables entre personas del mismo sexo. 3.2. Asuntos relativos a la filiación. 4. OTROS ASUNTOS RELEVANTES. 5. CONCLUSIONES. 6. BIBLIOGRAFÍA. 


\title{
LA ORIENTACIÓN SEXUAL ANTE EL TRIBUNAL EUROPEO DE DERECHOS HUMANOS
}

\author{
ESTELA GILBAJA CABRERO \\ Doctoranda y Colaboradora Honorífica en el Área \\ de Derecho Constitucional de la Universidad de Valladolid
}

\section{INTRODUCCIÓN}

El presente trabajo tiene por objeto el estudio de la jurisprudencia del Tribunal Europeo de Derechos Humanos (en adelante, TEDH o el Tribunal) en materia de orientación sexual.

La idea surge del análisis de la STC 198/2012, de 6 de noviembre, en la que se desestima el recurso de inconstitucionalidad interpuesto contra la Ley $13 / 2005^{1}$, que reconoce el derecho a contraer matrimonio entre personas del mismo sexo. De la argumentación de la referida Sentencia, ha llamado particularmente la atención de la doctrina ${ }^{2}$ la interpretación evolutiva del art. 32.1 $\mathrm{CE}^{3}$ que lleva a concluir que, aunque el constituyente no previó el matrimonio

${ }^{1}$ Ley 13/2005, de 1 de julio, por la que se modifica el Código Civil en materia de matrimonio.

2 Entre los comentarios a la citada Sentencia, pueden citarse el de Matia Portilla, Francisco Javier: «Interpretación evolutiva de la Constitución y legitimidad del matrimonio formado por personas del mismo sexo», Teoría y Realidad Constitucional, núm. 31, 2013, pp. 535-554; y los contenidos en el monográfico sobre El movimiento LGTB en perspectiva constitucional de la Revista General de Derecho Constitucional (núm. 17, 2013), por Arroyo GIL, Antonio: «De cómo por un mal camino se puede llegar a un buen sitio»; SALAZAR BENíTEZ, Octavio: «El matrimonio igualitario como exigencia del libre desarrollo de la afectividad y sexualidad»; Expósito, Enriqueta: «El derecho a contraer matrimonio entre personas del mismo sexo»; MarTín SÁNCHEZ, María: «El vago «sí» del Tribunal Constitucional»; y NARANJO DE LA Cruz, Rafael: «Matrimonio homosexual y categorías jurídicas».

3 Art. 32.1 CE: «el hombre y la mujer tienen derecho a contraer matrimonio con plena igualdad jurídica». 
entre personas del mismo sexo, éste no debe considerarse excluido por el citado precepto (FJ 9).

Para realizar dicha interpretación, el Tribunal Constitucional (en adelante, TC) parte de la noción de cultura jurídica, que engloba, además de los textos jurídicos, la realidad social jurídica relevante, el Derecho comparado, los tratados internacionales (y la jurisprudencia de los órganos que los interpretan) y las opiniones del sistema de Naciones Unidas ${ }^{4}$ y otros organismos internacionales. El TC señala el art. 10.2 $\mathrm{CE}^{5}$ como vía de entrada de estos elementos en nuestro sistema constitucional y, entre ellos, toma como base principal la jurisprudencia del TEDH, de cuya evolución deduce «que la institución del matrimonio como unión entre dos personas independientemente de su orientación sexual se ha ido asentando» (FJ 9).

Dicha evolución será lo que se estudie en los siguientes epígrafes, comentando las Sentencias del TEDH relativas al matrimonio entre personas del mismo sexo y ampliando la perspectiva al resto de asuntos en los que entra en juego la orientación sexual, desde las primeras Sentencias sobre el tema, en materia de Derecho Penal.

\section{ORIENTACIÓN SEXUAL Y DERECHO PENAL}

\subsection{Asuntos relativos a la probibición de las relaciones homosexuales}

La criminalización de la homosexualidad ha sido prácticamente constante a lo largo de la historia. Aunque en las antiguas civilizaciones, como las de Egipto, Grecia, Roma y China, contaba con la aceptación pública ${ }^{6}$, en la Edad Media la llegada a Europa del catolicismo y la confusión entre Iglesia y Estado hicieron que fuese considerada pecado y a su vez delito, concepción que ha

${ }^{4}$ Sobre la protección de los derechos de las personas LGTBI (lesbianas, gays, transexuales, bisexuales e intersexuales) en el ámbito de las Naciones Unidas, víd. ÁLVAREz Rodríguez, Ignacio: «La Organización de las Naciones Unidas y el derecho a la no discriminación por motivo de orientación sexual e identidad de género: apuntes para un debate», Revista General de Derecho Constitucional, núm. 17, 2013.

5 Art. 10.2 CE: «las normas relativas a los derechos fundamentales y a las libertades que la Constitución reconoce se interpretarán de conformidad con la Declaración Universal de Derechos Humanos y los tratados y acuerdos internacionales sobre las mismas materias ratificados por España».

${ }^{6}$ Martín SÁnChez, María: «Aproximación histórica al tratamiento jurídico y social dado a la homosexualidad en Europa», Estudios Constitucionales (Centro de Estudios Constitucionales de Chile, Universidad de Talca), núm. 1, 2011, pp. 245-276. 
persistido en los ordenamientos jurídicos de los países europeos ${ }^{7}$ hasta la segunda mitad del siglo $\mathrm{xx}^{8}$.

Puede tomarse como ejemplo el ordenamiento del Reino Unido, con unas Leyes aprobadas en 1861 y 1885 que prohibían las relaciones sexuales entre hombres ${ }^{9}$. Estas normas fueron modificadas en Inglaterra, Gales (en ambos en 1967) y Escocia (1980), despenalizando (con excepciones) los actos homosexuales consentidos entre dos hombres mayores de veintiún años, siguiendo las recomendaciones del Informe emitido en 1957 por el Departmental Committee on Homosexual Offences and Prostitution ${ }^{10}$.

7 En otras zonas, todavía existen numerosos países cuyos ordenamientos prohíben la homosexualidad y la castigan con pena de muerte —Afganistán, Arabia Saudí, Irán, Libia, Maldivas, Mauritania, Nigeria, Somalilandia, Sudán y Yemen (bttp://en.wikipedia.org/wiki/LGBT_rights_by_ country_or_territory, consultado el 17/12/2013)—. Muchos otros prevén pena de prisión, temporal o perpetua, además de otras penas como los castigos físicos, y prohíben los actos públicos en defensa de los derechos de las personas LGTBI u obvian los actos discriminatorios o violentos contra ellas (bttp://www.es.amnesty.org/temas/diversidad-afectivo-sexual, consultado el 07/02/2013).

${ }^{8}$ En España, en 1954 se incluyó a los homosexuales entre las personas susceptibles de ser declaradas «en estado peligroso» y sometidas a medidas de seguridad, previendo su internamiento en «un establecimiento de trabajo o Colonia Agrícola», separados de los demás internos, además de la prohibición de residir en determinado lugar o territorio, obligación de declarar su domicilio y sumisión a vigilancia (Ley de 15 de julio de 1954 por la que se modifican los artículos $2 .^{\circ}$ y $6 .^{\circ}$ de la Ley de Vagos y Maleantes, de 4 de agosto de 1933). La Ley 16/1970, de 4 de agosto, sobre peligrosidad y rehabilitación social, sustituye el lugar de internamiento por «un establecimiento de reeducación». Ya con la actual Constitución en vigor, la Ley 77/1978, de 26 de diciembre, de modificación de la Ley de Peligrosidad y Rehabilitación Social y de su Reglamento, suprime la homosexualidad de entre los supuestos de peligrosidad social, y la Ley Orgánica 10/1995, de 23 de noviembre, del Código Penal, deroga implícitamente la Ley de peligrosidad social e incluye la orientación sexual entre los motivos graves de discriminación (arts. 314, 510-512 y 515), siendo circunstancia agravante de la responsabilidad penal «cometer el delito por (...) discriminación referente a la (...) orientación sexual [de la víctima]» (art. 22). Un estudio más profundo sobre la evolución del Derecho penal español en relación con la homosexualidad puede verse en RoDRíGuEZ YAGÜE, Cristina: «Orientación sexual e identidad de género el proceso de consagración de derechos del colectivo LGTB», Revista General de Derecho Constitucional, núm. 15, 2012.

${ }^{9}$ La Offences against the Person Act 1861 castiga con cadena perpetua o pena de hasta 10 años de prisión la comisión o tentativa de sodomía; la Criminal Law Amendment Act 1885 prevé hasta dos años de prisión para el hombre que practique con otro un acto de "gross indecency» (indecencia grave) (§14).

${ }^{10}$ Según el citado informe del Departmental Committee on Homosexual Offences and Prostitution, la función del Derecho penal en materia de homosexualidad es "preservar el orden público y la decencia, proteger a los ciudadanos de lo que es ofensivo o injurioso y proporcionar protección suficiente contra la explotación y corrupción de otras personas, particularmente quienes son especialmente vulnerables por su juventud, debilidad física o mental, inexperiencia o estado de especial dependencia física, oficial o económica», pero no «intervenir en la vida privada de los ciudadanos 
En Irlanda del Norte, en cambio, se mantuvo la criminalización general de las citadas relaciones, cuestión de la que conoce el TEDH en el asunto Dudgeon c. Reino Unido, de 22 de octubre de 1981. Esta Sentencia da respuesta al recurso de un hombre que denuncia ser susceptible de persecución penal debido a su conducta homosexual, lo que se materializó en la investigación de que fue objeto tras hallarse, en un registro de su domicilio en busca de drogas, documentos personales reveladores de su orientación sexual. El Tribunal considera que la propia existencia de las normas que tipifican la homosexualidad constituye una injerencia continua y directa en el derecho del recurrente al respeto de su vida privada — que incluye su vida sexual ${ }^{11}$ — derecho que también resulta afectado por la investigación policial de que fue objeto. No obstante, la mera injerencia de los poderes públicos en el ejercicio del derecho no implica su lesión, pues queda justificada si está prevista en la Ley y es necesaria en una sociedad democrática (art. 8.2 CEDH) (§§ 41-44). Remitiéndose a anterior jurisprudencia según la cual la restricción de un derecho reconocido en el Convenio Europeo de Derechos Humanos (en adelante, CEDH o el Convenio) no puede ser calificada como «necesaria en una sociedad democrática» a menos que sea proporcionada al fin legítimo perseguido ${ }^{12}$, el Tribunal analiza si la prohibición penal de los actos homosexuales consentidos entre hombres mayores de veintiún años es proporcionada a la finalidad que alega el Gobierno del Reino Unido — la pro-

o pretender reforzar ningún modelo de comportamiento más allá de lo necesario para conseguir los objetivos citados». Asimismo, indica que el comportamiento homosexual entre adultos, consentido y en privado forma parte de la «moralidad y la inmoralidad privadas», que no son asunto de la ley y no debería estar penado.

11 En este sentido, la STEDH Laskey, Jaggard y Brown c. Reino Unido, de 19 de febrero de 1997, § 36: «la orientación y la actividad sexuales son aspectos íntimos de la vida privada».

${ }_{12}$ En el asunto W. c. Reino Unido, de 8 de julio de 1987, § 60, el TEDH sintetiza su jurisprudencia en relación con los límites del derecho reconocido en el art. $8 \mathrm{CEDH}$, el cual reconoce a toda persona el derecho al respeto de su vida privada y familiar, de su domicilio y de su correspondencia y añade que «no podrá haber injerencia de la autoridad pública en el ejercicio de este derecho sino en tanto en cuanto esta injerencia esté prevista por la ley y constituya una medida que, en una sociedad democrática, sea necesaria para la seguridad nacional, la seguridad pública, el bienestar económico del país, la defensa del orden y la prevención de las infracciones penales, la protección de la salud o de la moral, o la protección de los derechos y las libertades de los demás». Según la jurisprudencia del TEDH, la noción de necesidad implica que la injerencia responde a una necesidad social imperiosa y que los medios utilizados son proporcionales al fin legítimo perseguido. Además, aunque el objetivo esencial del art. 8 es proteger al individuo contra una injerencia arbitraria de las autoridades públicas, puede haber obligaciones positivas tendentes a un respeto efectivo del derecho. Por último, los Estados cuentan con un margen de apreciación que debe ser tenido en cuenta al determinar si una interferencia es «necesaria en una sociedad democrática» o si ha habido violación de una obligación positiva. 
tección de la moral y de los derechos y libertades de los demás_-, el cual aduce la existencia de notables diferencias entre la opinión pública de Irlanda del Norte y la del resto del Reino Unido y de una presión social que exige la medida. El Tribunal considera, sin embargo, que ni estas razones ni el nivel de riesgo para los miembros vulnerables de la sociedad son suficientes para limitar de tal modo los derechos reconocidos en el art. $8 \mathrm{CEDH}$, declarando, por quince votos contra cuatro, que el mismo ha sido vulnerado ${ }^{13}$ (\$\$ 53-63). De ello derivó la despenalización de la homosexualidad en Irlanda del Norte mediante la Homosexual Offences (Northern Ireland) Order 1982.

El TEDH resuelve en el mismo sentido los asuntos Norris c. Irlanda, de 26 de octubre de $1988^{14}$; Modinos $\boldsymbol{c}$. Chipre, de 22 de abril de 1993; y A. D. T. $\boldsymbol{c}$. Reino Unido, de 31 de julio de 2000; cuyos respectivos recurrentes denuncian la tipificación penal de las prácticas homosexuales consentidas entre hombres adultos $^{15}$. También en estos países se aprobaron normas despenalizando la homosexualidad $^{16}$.

13 Seis Magistrados emitieron cinco votos particulares (cuatro opiniones disidentes y una parcialmente disidente). En síntesis, Zekia considera que no hubo violación del Convenio, al entender que la prohibición de las relaciones sexuales entre hombres es necesaria para proteger la moral y los derechos de los demás. Por su parte, Evrigenis y García de Enterría entienden que debería haberse analizado la eventual violación del art. $14 \mathrm{CEDH}$ combinado con el 8, pues ven una diferencia de trato entre los hombres y las mujeres homosexuales, por una parte, y entre los homosexuales y los heterosexuales por otra. Matscher niega la violación del art. $8 \mathrm{CEDH}$, afirmando que éste no exige que el Estado trate la homosexualidad como una alternativa equivalente a la heterosexualidad y que el recurrente no puede considerarse víctima. También se oponen a su calificación como víctima Pinhero Farinha y Walsh, ya que la policía actuó aplicando la Drugs Act 1971 y no las leyes penales contra la homosexualidad.

${ }_{14}$ Del asunto Norris c. Irlanda, de 26 de octubre de 1988, cabe destacar que el recurrente, Senador, confesó su homosexualidad en un programa de televisión negando que fuera una enfermedad, lo que derivó en la presentación de una querella contra el programa por apología de las relaciones homosexuales, lo cual muestra que la tipificación de la homosexualidad afecta también a otros derechos, como la libertad de expresión (Rey Martínez, Fernando: «Homosexualidad y Constitución», Revista Española de Derecho Constitucional, núm. 73, 2005, pp. 111-156).

15 Actualmente se encuentra pendiente de resolución el asunto H. Ç. c. Turquía (recurso núm. 6428/12), recurso dirigido contra la existencia de leyes en la República Turca del Norte de Chipre que criminalizan ciertos actos homosexuales consentidos entre hombres adultos.

${ }^{16}$ En la República de Irlanda, The new Criminal Law (Sexual Offences) Act 1993; en Chipre, las sucesivas modificaciones del Código Penal (Law No. 40(1) of 1998 y Amending Law 77 (1)/2000) —aunque su art. 171 castiga con pena de prisión de cinco años las relaciones homosexuales que tengan lugar «en público»—; y en Reino Unido, la Sexual Offences Act 2003; http:// hudoc.echr.coe.int/sites/eng/pages/search.aspx? $i=001-55416,(\ldots) i=001-55580,(\ldots) i=001-56015$ y bttps://wcd.coe.int/ViewDoc.jsp? Ref=CM/Del/OJ/DH(2004)897, consultado el 23/03/2013. Ha de destacarse que en el año 2000 entró en vigor en Reino Unido la Human Rights Act 1998, que 
Algunos ordenamientos, a pesar de la despenalización general de la homosexualidad, mantuvieron su tipificación en el ámbito militar. Es el caso de Reino Unido, con la Army and Air Force Acts $1955^{17}$ y la Naval Discipline Act $1957^{18}$, cuya aplicación dio lugar a las Sentencias Lustig-Prean y Beckett c. Reino Unido, de 27 de septiembre de 1999; Smith y Grady c. Reino Unido, de 27 de septiembre de 1999; Beck Copp y Bazeley c. Reino Unido, de 22 de octubre de 2002; y Perkins y R. c. Reino Unido, de 22 de octubre de 2002, asuntos referidos a la investigación de la orientación sexual de varios miembros de las fuerzas armadas y su posterior expulsión fundada en su homosexualidad. En todos ellos el TEDH concluye por unanimidad que se ha producido una injerencia injustificada en el derecho reconocido en el art. $8 \mathrm{CEDH}$. Tras las dos primeras Sentencias citadas, el Gobierno del Reino Unido aprobó un código de conducta (The Armed Forces Code of Social Conduct Policy Statement), no solamente acabando con la prohibición de que los homosexuales formen parte de la armada, sino además prohibiendo la discriminación basada en la orientación sexual ${ }^{19}$.

\subsection{Asuntos relativos a la edad de consentimiento para las relaciones sexuales}

Por otra parte, al TEDH se le ha planteado la cuestión de la edad de consentimiento para las relaciones sexuales, que en algunos ordenamientos es diferente

dispone que los Juzgados y Tribunales deben tener en cuenta las resoluciones del TEDH cuando conozcan de una cuestión relacionada con un derecho reconocido en el CEDH (concretamente en los arts. 2-12 y 14 del CEDH, $1-3$ del Protocolo n. ${ }^{\circ} 1$ y 1 del Protocolo n. ${ }^{\circ} 13$ ) y que el ordenamiento del Reino Unido debe interpretarse y aplicarse de modo compatible con los derechos del CEDH (arts. 1-3 Human Rights Act 1998; bttp://www.legislation.gov.uk/ukpga/1998/42, consultado el 11/04/2013). La promulgación de esta norma se debe a la observación de que los jueces poseían un excesivo poder a la hora de interpretar los derechos; para profundizar sobre este asunto, víd. Alonso García, Ricardo y Torres Muro, Ignacio: «La ley de derechos humanos (Human Rights Act 1998): una evolución a conciencia», Revista Española de Derecho Administrativo, núm. 105, 2000, pp. 5-36.

17 El art. 66 Army and Air Force Acts 1955 dispone que toda persona sujeta a la ley militar que sea culpable de conducta vergonzosa de modo cruel, indecente o antinatural, en caso de ser condenada por un tribunal militar, podrá ser castigada con pena de prisión de hasta dos años o uno de los castigos menores previstos por esta Ley (bttp://www.legislation.gov.uk/ukpga/Eliz2/3-4/18, consultado el 19/02/2013).

${ }^{18} \mathrm{El}$ art. 37 Naval Discipline Act 1957 establece que toda persona sujeta a esta Ley que sea culpable de alguna conducta vergonzosa de tipo indecente podrá ser despedida con deshonra del servicio de Su Majestad o ser castigada a una pena menor de las autorizadas por esta Ley (bttp:// www.legislation.gov.uk/ukpga/Eliz2/5-6/53, consultado el 19/02/2013).

19 http://hudoc.echr.coe.int/sites/eng/pages/search.aspx? i=001-56395 y http://www.proud2serve.net/ military-law-a-codes/213-armed-forces-code-of-social-conduct, consultado el 23/03/2013. 
según se trate de dos personas del mismo o de distinto sexo. Es el asunto resuelto, entre otras, en las Sentencias L. $\boldsymbol{y} \boldsymbol{V}$. c. Austria, de 9 de enero de 2003, y S. L. c. Austria, de 9 de enero de 2003, cuyos respectivos recurrentes alegan que el art. 209 del Código Penal austriaco, que criminaliza los actos homosexuales consentidos entre un hombre mayor de diecinueve años y un adolescente de entre catorce y dieciocho, viola su derecho a la vida privada y es discriminatorio, ya que las relaciones heterosexuales o entre mujeres en el mismo margen de edad no son punibles. El TEDH examina la cuestión a la luz de los arts. 8 y 14 $\mathrm{CEDH}^{20}$ considerados conjuntamente. La aplicación del primero no se discute, pues la orientación sexual es uno de los aspectos más íntimos de la vida privada ${ }^{21}$. En cuanto al art. 14, recuerda que, de acuerdo con su jurisprudencia, una diferencia de trato es discriminatoria, en el sentido de este precepto, si no tiene una justificación objetiva y razonable, es decir, si no persigue un fin legítimo o si no hay una relación razonable de proporcionalidad entre los medios empleados y el fin perseguido ${ }^{22}$. No obstante, los Estados tienen un cierto margen de apreciación ${ }^{23}$ en cuanto a la determinación de cuándo y en qué medida está justificada

${ }^{20} \mathrm{El}$ art. $14 \mathrm{CEDH}$ prohíbe la discriminación en los siguientes términos: «el goce de los derechos y libertades reconocidos en el presente Convenio ha de ser asegurado sin distinción alguna, especialmente por razones de sexo, raza, color, lengua, religión, opiniones políticas u otras, origen nacional o social, pertenencia a una minoría nacional, fortuna, nacimiento o cualquier otra situación». Según la jurisprudencia del TEDH, el art. $14 \mathrm{CEDH}$ no tiene existencia independiente, ya que su eficacia va ligada al disfrute de los derechos y libertades garantizados por el Convenio. No obstante, una medida, siendo en sí misma conforme al precepto que consagra el derecho o la libertad de que se trate, puede vulnerar dicho precepto combinado con el art. 14 CEDH si es discriminatoria. Además, la prohibición de discriminación que consagra el art. 14 CEDH va más allá del propio Convenio y sus Protocolos: se aplica también a los derechos adicionales que el Estado en cuestión haya decidido proteger. En este sentido, cabe citar, en primer lugar, el asunto «relativo a ciertos aspectos del régimen lingüístico de la enseñanza en Bélgica»c. Bélgica, de 23 de julio de 1968, En Droit, I. B, § 9; y, entre las posteriores, las SSTEDH Abdulaziz, Cabales y Balkandali c. Reino Unido, de 28 de mayo de 1985, § 71; Karlheinz Schmidt c. Alemania de 18 de julio de 1994, § 22; Van Raalte c. Países Bajos, de 21 de febrero de 1997, § 33; Petrovic c. Austria, de 27 de marzo de 1998, § 22; y Fretté c. Francia, de 26 de febrero de 2002, § 27.

${ }^{21}$ Así se indica, entre otras, en las SSTEDH Dudgeon c. Reino Unido, de 22 de octubre de 1981, § 52; y Smith y Grady c. Reino Unido, de 27 de septiembre de 1999, § 90.

${ }_{22}$ Este razonamiento se conoce como «test de proporcionalidad»o «principio de proporcionalidad».

${ }^{23}$ El margen de apreciación nacional es, de forma muy resumida y en palabras de Javier García Roca, «un límite estructural que permitiría no entrar a revisar, en ciertos casos, la interferencia en el derecho, o contentarse con hacer un simple escrutinio liminar, si, a primera vista, el fin de la restricción parece legítimo en Estrasburgo, la medida y la regulación son necesarias a ojos de la Corte Europea, que decide contenerse en su juicio por muy variados motivos conexos a la lógica de la subsidiariedad» (GARCía Roca, Francisco Javier: El margen de apreciación nacional en 
una diferencia de trato en situaciones similares (L. y V.c. Austria, § 44). Al igual que las diferencias basadas en el sexo, las fundadas en la orientación sexual, la cual se engloba en el art. $14 \mathrm{CEDH}^{24}$, requieren razones particularmente serias para estar justificadas ${ }^{25}$ (ibid., § 45). No apreciando la existencia de ninguna razón objetiva y razonable que justifique la diferencia de trato, el Tribunal concluye en ambos casos, por unanimidad, que ha habido violación de los arts. 8 y $14 \mathrm{CEDH}$.

Aunque, en el curso de los citados procedimientos, en 2002 se derogó el controvertido art. 209 del Código Penal austriaco ${ }^{26}$, han seguido llegando casos al TEDH, como el reciente asunto E. B. y otros $\boldsymbol{c}$. Austria, de 7 de noviembre de 2013, en el que, siguiendo la misma argumentación, se declara por unanimidad la vulneración de los arts. 8 y $14 \mathrm{CEDH}$. A igual solución se llega en el caso B. B. c. Reino Unido, de 10 de febrero de 2004, país en el que, posteriormente a la interposición del recurso, entró en vigor la Sexual Offences (Amendment) Act 2000.

\section{ORIENTACIÓN SEXUAL Y VIDA FAMILIAR}

Al contrario que en materia de Derecho penal, donde la opinión del TEDH está claramente definida y no se le plantean dudas a la hora de determinar cuándo hay vulneración de derechos basada en la orientación sexual, en lo relativo a la vida familiar de las personas homosexuales la resolución de los asuntos es más compleja, como se verá en los siguientes párrafos. Además, se trata de una mate-

la interpretación del Convenio Europeo de Derechos Humanos: soberanía e integración. Civitas, Pamplona, 2010, pp. 91-92).

${ }^{24}$ En este sentido, la STEDH Salgueiro da Silva Mouta c. Portugal, de 21 de diciembre de $1999, \S 28$, dice que ha habido una diferencia de trato que se basa en la orientación sexual del recurrente, noción que está cubierta, sin lugar a dudas, por el art. 14 del Convenio.

${ }^{25}$ Es lo que se conoce como «doctrina de las clasificaciones normativas sospechosas», que son las diferencias de trato jurídico que se perciben como gravemente odiosas para la dignidad de la persona por basarse en circunstancias como la raza, el sexo u otras causas entre las que se sitúa la orientación sexual [CARMONa CuenCa, Encarna: «La prohibición de discriminación. Nuevos contenidos. (Art. 14 CEDH y Protocolo 12)», García Roca, Javier y Santolaya MachetTi, Pablo [Coords.]: La Europa de los Derechos. El Convenio Europeo de Derechos Humanos. Centro de Estudios Políticos y Constitucionales, Madrid, 2009, pp. 733-764].

26 http://budoc.echr.coe.int/sites/eng/pages/search.aspx? $i=001-83641$, consultado el 26/02/2013. Comenta Omar Bouazza que la reforma no afecta a los casos ya juzgados y se ha configurado un sistema de indultos discrecionales que dependen de la conducta del imputado (BouAZZA ARIÑo, Omar: «Tribunal Europeo de Derechos Humanos», Revista General de Derecho Administrativo, núm. 11, 2006). 
ria de plena actualidad, pues desde hace unos años se encuentra en el orden del día de las modificaciones legislativas. Por ello, como se verá, no puede señalarse de forma tajante cuál es la posición del TEDH, ya que ésta ha ido evolucionando y tiene presentes los cambios legislativos cuando se trata de fijar la amplitud del margen de apreciación nacional.

\subsection{Matrimonio y otras formas de reconocimiento jurídico de las relaciones estables entre personas del mismo sexo}

Los primeros asuntos que llegan al TEDH en materia de reconocimiento jurídico de las relaciones estables entre personas del mismo sexo se refieren a la negación a estas parejas de beneficios previstos en principio para las heterosexuales. Así sucede en el asunto Mata Estévez c. España, cuya admisibilidad rechaza el Tribunal (Decisión de 10 de mayo de 2001). El recurrente, que había convivido durante diez años con otro hombre, tras la muerte de éste solicitó las prestaciones previstas por la Seguridad Social para los cónyuges supervivientes, que le fueron rechazadas. Apelando a «la jurisprudencia constante de los órganos del Convenio», afirma el Tribunal que las relaciones homosexuales duraderas entre dos hombres no están protegidas por el derecho al respeto a la vida familiar reconocido en el art. $8 \mathrm{CEDH}$ y que, a pesar de la evolución de varios Estados europeos tendente al reconocimiento legal y jurídico de las uniones de hecho estables entre homosexuales, se trata de una materia en la que los Estados gozan de un gran margen de apreciación. No obstante, sí considera aplicable el art. 8 $\mathrm{CEDH}$ en tanto que protector de la vida privada, precepto cuya violación evalúa en conjunción con el art. 14, concluyendo que no hay lesión puesto que la eventual diferencia de trato quedaría amparada por el margen de apreciación, ello añadido a la legitimidad del objetivo perseguido por la norma: la protección de la familia fundada en el vínculo del matrimonio, reservado en aquel momento a las parejas heterosexuales.

Se aprecia un avance en la posición del Tribunal en la STEDH Karner c. Austria, de 24 de julio de $2003^{27}$. El Sr. Karner convivía con otro hombre en un piso alquilado por este último. Al morir el arrendatario, el propietario de la vivienda inició un proceso para poner fin al uso de la misma, a lo que se opusieron diversas administraciones públicas, las cuales consideran aplicable a las

${ }^{27}$ Un estudio más detallado de esta Sentencia es el de Frumer, Philippe: «La discrimination fondée sur l'orientation sexuelle dans les relations de partenariat ou de cohabitation: une question d'intérêt général devant la Cour Éuropéenne des Droits de l'Homme (l'arrêt Karner c. l'Autriche du 14 juillet 2003)», Revue trimestrielle des droits de l'homme, núm. 59, 2004, pp. 663-687. 
relaciones homosexuales el art. 14(3) de la Ley que regula el arrendamiento ${ }^{28}$, que permite continuar en la vivienda a la pareja del arrendatario fallecido. A esta visión se opone la Corte Suprema, dando la razón al propietario (§ 15). El Sr. Karner acude al TEDH alegando ser víctima de discriminación basada en su orientación sexual, por lo que invoca los arts. 14 y 8 TEDH. En esta ocasión, el Tribunal no entra a considerar si la expresión «vida familiar» del art. 8 CEDH protege a las parejas homosexuales; no considera necesario determinar tal noción ni la de «vida privada» ${ }^{29}$, puesto que la demanda del recurrente se refiere a una diferencia de trato perjudicial que afecta al disfrute de su derecho al respeto de su domicilio, garantizado por el citado precepto. Asimismo, señala que el recurrente convivió en el piso con el arrendatario y que, si no hubiera sido por su sexo o su orientación sexual, podría haber sido aceptado como pareja a los efectos del art. 14(3) de la Ley de arrendamiento (\$ 33). El Gobierno admite una diferencia de trato basada en la orientación sexual, que justifica afirmando que el art. 14(3) de la Ley de arrendamiento va dirigido a la protección de la «familia tradicional» ( $\$ 35)$, objetivo que el Tribunal «puede aceptar» como, «en principio», legítimo; sin embargo, atendiendo a las circunstancias del caso, entiende que no respeta el principio de proporcionalidad ( $(40)$, puesto que, para que ello ocurra, en un caso de diferencia de trato basada en el sexo o en la orientación sexual, no es suficiente con que la medida sirva para el fin perseguido sino que, además, hay que probar que, para alcanzar éste, es necesario excluir ciertas categorías de personas, en este caso aquéllas que viven en una relación homosexual ( $\$ 41)$. Por

${ }^{28} \mathrm{El}$ art. 14 Bundesgesetz vom 12. November 1981 über das Mietrecht (Mietrechtsgesetz - MRG), BGBl. Nr. 520/1981 (Ley Federal sobre la posesión —-Ley de Arrendamiento-) regula la posesión en caso de muerte: (1) La muerte del arrendador o del arrendatario no cancela el arrendamiento. (2) A la muerte del principal poseedor de un piso, las personas designadas en el apartado 3 como titulares del derecho a suceder en la posesión deberán hacerlo, en exclusión de otras personas, salvo que, en el plazo de 14 días, hayan notificado al propietario que no desean continuar con la posesión (...). (3) (...) serán susceptibles de suceder en la posesión en el sentido del apartado 2: el cónyuge, el «compañero de vida» —Lebensgefäbrte—, parientes (...). En el sentido de este precepto, Lebensgefährte se refiere a la persona que ha convivido en el piso con el poseedor formal hasta la muerte de éste durante al menos tres años, compartiendo un hogar en un régimen económico como el de un matrimonio (...) (bttp://www.ris.bka.gv.at/GeltendeFassung.wxe? Abfrage =BundesnormenEGesetzesnummer $=10002531$, consultado el 05/03/2013; Karner c. Austria, de 24 de julio de 2003, § 19).

29 El no entrar a determinar las nociones de «vida privada» y «vida familiar» supuso, en opinión de Elizabeth Kukura, perder una oportunidad de avanzar en el reconocimiento de derechos de las minorías sexuales a la luz del CEDH (KuKurA, Elizabeth: «Finding Family: Considering the Recognition of Same-Sex Families in International Human Rights Law and the European Court of Human Rights», Human Rights Brief 13, núm. 2, 2006, pp. 17-20). 
tanto, el TEDH declara, por seis votos contra uno ${ }^{30}$, que hubo violación del art. $14 \mathrm{CEDH}$ combinado con el art. 8. En la misma línea resuelve los asuntos Kozak c. Polonia, de 2 de marzo de 2010; P. B. y J. S. c. Austria, de 22 de julio de 2010; y J. M. c. Reino Unido, de 28 de septiembre de $2010^{31}$.

La primera oportunidad que tuvo el TEDH de examinar si dos personas del mismo sexo tienen derecho a contraer matrimonio fue al estudiar el asunto Schalk y Kopf c. Austria, de 24 de junio de $2010^{32}$, en el que los citados Sres. Schalk y

${ }^{30}$ No hubo unanimidad porque el Magistrado Grabenwarter, coincidiendo en que hubo violación del art. $14 \mathrm{CEDH}$ combinado con el 8, votó en contra de la mayoría por entender que el asunto no debía haberse resuelto ya que el recurrente había muerto y no tenía herederos legales que le sucedieran en el proceso.

31 El asunto Kozak c. Polonia, de 2 de marzo de 2010, se refiere también a la sucesión en la tenencia del domicilio común de una pareja del mismo sexo. En el caso que resuelve la STEDH P. B. yJ. S. c. Austria, de 22 de julio de 2010 , la discriminación se produjo al denegar a los recurrentes su solicitud de inclusión de uno de ellos en el seguro del otro, ya que la Ley preveía la inclusión de la persona de sexo diferente del asegurado que conviva con éste y realice para él el trabajo doméstico sin remuneración; en 2007 se eliminó la referencia explícita a la pareja de sexo diferente (§§ 45-50). La STEDH J. M. c. Reino Unido, de 28 de septiembre de 2010, resuelve el recurso de una mujer que sufrió una diferencia de trato en la fijación de la pensión de manutención de sus hijos. Al no aplicársele el art. 6(5) de la Ley sobre la manutención de menores (Child Support Act 1991), que exigía tener en cuenta la convivencia del progenitor ausente «con otro adulto del sexo opuesto», la cantidad resultante fue cuatro veces mayor que si se tratara de una pareja heterosexual, produciéndose una violación del art. $14 \mathrm{CEDH}$ combinado con el art. 1 del Protocolo n. ${ }^{\circ}$ 1, que protege la propiedad. La Civil Partnership Act 2004 modificó dicha norma con el fin de que se tenga en cuenta la convivencia del progenitor con otro adulto del mismo sexo, sean o no pareja registrada (bttp://www. legislation.gov.uk/ukpga/2004/33/enacted, consultado el 18/03/2013).

32 En ocasiones anteriores había llegado al TEDH la cuestión del matrimonio de las personas transexuales. La evolución en el reconocimiento de los derechos de las personas homosexuales, que estudiamos en el presente trabajo, también se ha producido en relación con las transexuales. Así, en materia de matrimonio, en los primeros casos (Rees c. Reino Unido, de 17 de octubre de 1986; Cossey c. Reino Unido, de 27 de septiembre de 1990; y Sheffield y Horsham c. Reino Unido, de 30 de julio de 1998), no se considera violado el art. $12 \mathrm{CEDH}$, afirmando que el concepto tradicional de matrimonio se basa en la unión de personas de diferente sexo biológico y que corresponde a los Estados regular el derecho a contraerlo. No obstante, en Sheffield y Horsham c. Reino Unido, se menciona la creciente aceptación social de la transexualidad. El gran cambio se produce con la STEDH Christine Goodwin c. Reino Unido, de 17 de julio de 2002, en la que el Tribunal declara la violación del art. $12 \mathrm{CEDH}$, indicando que no hay justificación para excluir totalmente a las personas transexuales del matrimonio, aunque las condiciones concretas las fijará el Estado. Tras esta Sentencia, se introdujo en Reino Unido un sistema que permite a las personas transexuales obtener un certificado de reconocimiento de género (bttp://www.echr.coe.int/NR/rdonlyres/6E6BBODC-A41D-4ADB-94B337407490C629/0/FS_Gender_identity_ENG.pdf, consultado el 24/03/2013). Un estudio de la jurisprudencia del TEDH en materia de transexualidad puede verse en RuIZ-RISUEÑo MonTOYA, Francisco M.: «Los derechos de las personas LGBT en la jurisprudencia del Tribunal Europeo de Derechos Humanos», Revista General de Derecho Constitucional, núm. 17, 2013.

N.o 91, septiembre-diciembre 2014, págs. 303-340 
Kopf recurren la denegación de su solicitud de inicio de los trámites para contraer matrimonio. El Tribunal recuerda su jurisprudencia anterior relativa al art. $12 \mathrm{CEDH}^{33}$, según la cual este precepto garantiza el derecho a contraer matrimonio y a fundar una familia al hombre y la mujer y, del conjunto del Convenio y del contexto histórico en que fue adoptado (1950), se deduce que la expresión ${ }^{34}$ es deliberada, aunque aisladamente pudiera entenderse que no excluye el matrimonio entre dos personas del mismo sexo ( $\$ \$ 4$ y 55). Esta última es la interpretación de los recurrentes, que aluden a la jurisprudencia del TEDH que dice que el Convenio es un instrumento vivo que debe interpretarse según las condiciones presentes $^{35}$, y opinan que el art. 12 debería entenderse como garantía del acceso de las parejas del mismo sexo al matrimonio o, en otras palabras, como mandato a los Estados miembros para que permitan tal acceso en sus ordenamientos ( $\$ 57)$. Sin embargo, el TEDH no va tan lejos.

Respecto al art. 9 de la Carta de los Derechos Fundamentales de la Unión Europea $^{36}$, que elude la referencia al hombre y la mujer al hablar del derecho a contraer matrimonio, señala que tal elusión es deliberada y deja la decisión de permitir el matrimonio entre personas del mismo sexo a las leyes nacionales ${ }^{37}$ ( $\S$ 60). Teniendo presente esto último, el TEDH dice que ya no puede afirmarse que el derecho a contraer matrimonio consagrado en el art. $12 \mathrm{CEDH}$ deba en todo caso estar limitado a las parejas de sexo opuesto. Sin embargo, teniendo en

$33 \mathrm{El}$ art. $12 \mathrm{CEDH}$ dispone que «a partir de la edad núbil, el hombre y la mujer tienen derecho a casarse y a fundar una familia según las leyes nacionales que rijan el ejercicio de este derecho».

${ }^{34}$ En la versión en inglés: «men and women of marriageable age have the right to marry and to found a family (...)»; en la versión en francés: «à partir de l'âge nubile, l'homme et la femme ont le droit de se marier et de fonder une famille (...)».

35 Entre otras, Christine Goodwin c. Reino Unido, de 17 de julio de 2002, §§ 74-75; y E. B. c. Francia, de 22 de enero de 2008, § 92.

${ }^{36} \mathrm{El}$ art. 9 de la Carta establece que «se garantizan el derecho a contraer matrimonio y el derecho a fundar una familia según las leyes nacionales que regulen su ejercicio».

37 Así, el Comentario a la Carta de los Derechos Fundamentales de la Unión Europea explica que «con el objeto de tener en cuenta la diversidad de regulaciones internas sobre el matrimonio, el art. 9 de la Carta se refiere a la legislación nacional. (...) [L]a disposición es más amplia en su alcance que los artículos correspondientes de otros instrumentos internacionales. Dado que no hay referencia explícita a «hombres y mujeres» como es el caso de otros instrumentos de derechos humanos, puede decirse que no hay obstáculo para reconocer las relaciones del mismo sexo en el contexto del matrimonio. Tampoco hay, sin embargo, requerimiento explícito de que las leyes nacionales deban facilitar dichos matrimonios», Commentary of the Charter of Fundamental Rights of the European Union, p. 102 (bttp://ec.europa.euljusticelfundamental-rights/files/networkcommentaryfinal_ en.pdf, consultado el 5/12/2012). En este sentido, la STEDH Christine Goodwin c. Reino Unido, de 17 de julio de 2002, $§ 100$. 
cuenta que aún no existe consenso a nivel europeo sobre la materia, es una opción del Derecho interno de los Estados ( $\$ 61$ ), aunque éstos no pueden introducir limitaciones que restrinjan o reduzcan el derecho de modo que su contenido esencial se vea perjudicado ${ }^{38}(\S 49)$. Por todo ello declara, por unanimidad, que no hay violación del art. $12 \mathrm{CEDH} \mathrm{( \$} \mathrm{64).}$

Para analizar la posible violación del art. $14 \mathrm{CEDH}$ combinado con el 8, el TEDH estudia la aplicabilidad al caso de estos preceptos. Aunque es indiscutible que la relación de una pareja del mismo sexo se engloba en la noción de «vida privada», el Tribunal considera apropiado dilucidar si constituye también «vida familiar» (\$90). Según su jurisprudencia respecto a las parejas de diferente sexo, la noción de familia no está restringida a relaciones basadas en el matrimonio y puede englobar otros vínculos «familiares» de facto ${ }^{39}$ (§ 91). Sin embargo, hasta esta Sentencia sólo había aceptado que la relación afectiva y sexual de una pareja homosexual constituye «vida privada» pero no «vida familiar». Es en este momento cuando, a la vista de la tendencia, en varios Estados europeos y en disposiciones de la UE, hacia el reconocimiento legal de las relaciones estables entre personas del mismo sexo y a incluirlas en la noción de «familia», el TEDH considera artificial mantener su visión anterior y afirma que la relación estable de facto de una pareja del mismo sexo que convive se engloba en la noción de «vida familiar» igual que la de personas de diferente sexo (\$§ 92-94) y necesita igualmente reconocimiento y protección legales (\$ 99).

Volviendo al caso concreto, el Tribunal da respuesta a la alegación de los recurrentes sobre la discriminación que afirman haber sufrido por ser una pareja del mismo sexo, por una parte, por no tener acceso al matrimonio ni medios alternativos para reconocer su relación hasta que entró en vigor la Ley de Parejas Registradas $^{40}$ ( $(100)$ y, por otra, porque hay diferencias entre el estatus del matrimonio y el de la pareja registrada ( $\$ 107)$. En cuanto a lo primero, el Tribunal recuerda que el CEDH debe leerse en conjunto y si, como dijo más arriba,

${ }^{38}$ En este sentido, pueden citarse los asuntos Rees c. Reino Unido, de 17 de octubre de 1986, $\S 50 ;$ F. c. Suiza, de 18 de diciembre de 1987, § 32; y B. y L. c. Reino Unido, de 13 de septiembre de $2005, \S 34$.

39 Así, se dice en la STEDH Berrehab c. Países Bajos, de 21 de junio de 1988, § 21, que un niño nacido en una relación familiar de facto es ipso iure parte de esa relación; existe entre él y sus progenitores una «vida familiar» incluso si éstos no viven juntos.

40 Eingetragene Partnerschaft-Gesetz, BGBl. I - Ausgegeben am 30. Dezember 2009 - Nr. 135. Regula el establecimiento, los efectos y la resolución de la unión registrada de parejas del mismo sexo (art. 1) y dispone en su art. 2 que una pareja registrada sólo puede estar formada por dos personas del mismo sexo, que se unen para permanecer juntos toda la vida con derechos y obligaciones recíprocos (bttp://www.ris.bka.gv.at/Dokumente/BgblAutb/BGBLA_2009_I_135/ BGBLA_2009_I_135.pdf, consultado el 04/12/2012). 
el art. 12 no obliga a los Estados a garantizar a las parejas del mismo sexo el acceso al matrimonio, el art. 14 combinado con el 8 no puede interpretarse de modo que imponga tal obligación ( $§ 101)$. Dado que en el momento de la Sentencia los recurrentes tienen la posibilidad de crear una pareja registrada, el Tribunal no examina si la falta absoluta de medios de reconocimiento legal de las parejas del mismo sexo vulnera el art. 14 combinado con el 8, sino si el Estado lo debería haber permitido antes. La respuesta es negativa, habida cuenta del escaso consenso sobre la materia, que hace que los Estados deban gozar de un margen de apreciación en cuanto al tiempo de introducción de cambios legislativos ( $§ 103-105)$ así como en relación con el estatus conferido por medios alternativos de reconocimiento ( $§ 108)$. Así, el Tribunal considera que el Estado no ha excedido su margen de apreciación confiriendo a las parejas registradas un estatus similar al del matrimonio con ciertas diferencias respecto a los derechos parentales ( $\$ 109)$, declarando, por cuatro votos contra tres, la no violación del art. $14 \mathrm{CEDH}$ combinado con el $8^{41}$ (\$ 110).

Cabe citar aquí el asunto Chapin y Charpentier c. Francia (recurso núm. 40183/07), cuyos recurrentes contrajeron matrimonio en un ayuntamiento y la Administración lo anuló. El TEDH no llegó a resolverlo y a día de hoy las parejas del mismo sexo pueden contraer matrimonio en Francia, tras la aprobación de la LOI $n^{\circ}$ 2013-404 du 17 mai 2013 ouvrant le mariage aux couples de personnes de même sexe $e^{42}$.

Por lo general, antes de reconocer a las parejas del mismo sexo el derecho a contraer matrimonio, o sin plantearse dar ese paso, los Estados que deciden darles cierto reconocimiento jurídico promulgan leyes de uniones civiles, como ocurrió, entre otros, en Francia con el pacte civil de solidarité (en adelante, PACS) ${ }^{43}$,

${ }^{41}$ Acompañan a la Sentencia la opinión disidente conjunta de los Magistrados Rozakis, Spielmann y Jebens y la opinión concurrente de Malinverni, al que se une Kovler. Los primeros consideran que sí hubo violación del art. $14 \mathrm{CEDH}$ combinado con el 8 y que el fallo es incoherente, pues el Tribunal equipara las parejas estables del mismo sexo y las de distinto, afirmando que ambas necesitan reconocimiento legal y protección, y deja después tal reconocimiento en manos de los Estados amparándose en el margen de apreciación, a pesar de que el Gobierno no fue capaz de dar argumentos que justifiquen la diferencia de trato basada en la orientación sexual. La opinión concurrente se refiere a lo afirmado respecto al art. $12 \mathrm{CEDH}$. Los firmantes coinciden en que éste no se lesionó pero no suscriben los argumentos de la mayoría, ya que opinan que en ningún caso puede entenderse referido a las parejas del mismo sexo.

${ }^{42}$ La citada Ley confiere al art. 143 CC francés la siguiente redacción: «el matrimonio es contraído por dos personas de sexo diferente o del mismo sexo» (bttp://legifrance.gouv. frlaffichTexte. do?cidTexte=JORFTEXTO00027414540EcategorieLien $=i d$, consultado el 19/12/2013).

43 Según el art. 515-1 del Código Civil francés, un pacto civil de solidaridad es un contrato firmado por dos personas físicas mayores de edad, de sexo diferente o del mismo sexo, para orga- 
previsto para cualquier pareja, y en Austria con la citada Eingetragene Partnerschaft-Gesetz, solamente para las homosexuales.

En otros países, por el contrario, los avances sociales han llevado a prever una figura jurídica para las parejas de hecho pero se excluye a las del mismo sexo. Es el caso de Grecia, donde, a pesar de la oposición de la Comisión Nacional de Derechos Humanos por considerar tal exclusión discriminatoria, se promulgó la Ley núm. 3719/2008, estudiada por el TEDH en el asunto Vallianatos y otros c. Grecia, de 7 de noviembre de 2013. Los recurrentes (tres parejas del mismo sexo y una asociación que apoya a personas homosexuales) no sostienen que el Estado esté obligado a proporcionar reconocimiento legal a las parejas del mismo sexo, sino que la Ley 3719/2008 introduce una distinción discriminatoria. En primer lugar, el Tribunal constata que la situación de los recurrentes es comparable a la de las parejas del mismo sexo que deseen constituir una unión civil, pues necesitan del mismo modo reconocimiento y protección legales ( $§ 78)$. El Tribunal observa que la citada Ley reserva expresamente la posibilidad de crear una unión civil a dos individuos de diferente sexo, excluyendo tácitamente a las parejas del mismo sexo, lo que supone una diferencia de trato basada en la orientación sexual (\$ 79). Para justificar tal exclusión, el Gobierno afirma que aquéllas pueden regular su convivencia con un contrato ordinario y que la referida legislación tiene entre sus objetivos proteger a los hijos nacidos fuera del matrimonio y reforzar las instituciones del matrimonio y la familia en el sentido tradicional ( $\$ 80)$. El Tribunal considera que, aunque son fines legítimos ( $\$ 83)$, dado que el Convenio es un instrumento vivo el Estado debe tener en cuenta la evolución de la sociedad y los cambios en la percepción del estatus social y civil de las relaciones (§ 84). Además, al tratarse de una diferencia de trato basada en la orientación sexual, el Gobierno debe justificar que para lograr el fin perseguido es necesario excluir a las parejas del mismo sexo de las uniones civiles ( $\$ 85)$, cosa que no hace (§ 92), por lo que el Tribunal declara, por dieciséis votos contra uno, que ha habido una violación de los arts. 8 y $14 \mathrm{CEDH}^{44}$.

El reconocimiento jurídico de las parejas homosexuales, mediante el matrimonio o a través de otro tipo de unión, da lugar a diferentes controversias, como los problemas de reconocimiento de tales uniones fuera del Estado de celebración - tema que se plantea en el asunto Taddeucci y McCall c. Italia

nizar su vida en común (bttp://www.legifrance.gouv. fr/affichCode.do?cidTexte $=$ LEGITE XT000006070721, consultado el 12/03/2013).

44 El Magistrado Pinto de Albuquerque votó en contra del fallo por considerar, como expone en su opinión parcialmente concurrente, que el asunto debió inadmitirse por no haber sido agotados los recursos internos, lo que impidió a los tribunales griegos examinar la eventual violación del Convenio. 
(recurso núm. 51362/09), pendiente de resolución ${ }^{45}$ - o la cuestión de la objeción de conciencia de los funcionarios que se niegan a formalizar tales uniones, analizada en la STEDH Eweida y otros c. Reino Unido, de 15 de enero de 2013, que da respuesta a varios recursos. Nos interesa el de la tercera recurrente, que perdió su trabajo tras negarse a ser designada como registradora de uniones civiles ${ }^{46}$ debido a que, según su religión (cristiana), entiende que las uniones civiles entre personas del mismo sexo son «contrarias a la voluntad de Dios», y se considera víctima de una discriminación basada en su religión, por la ausencia de diferencia de trato en comparación con los compañeros que no tienen objeción de conciencia a las uniones homosexuales $(\$ \S$ 102-104). El Tribunal, teniendo presente que las diferencias de trato basadas en la orientación sexual requieren razones particularmente serias para ser justificadas, declara, por dos votos contra cinco, la no violación del Convenio, puesto que el fin perseguido por la medida - proporcionar un servicio eficiente y que cumpla con el objetivo público de promover la igualdad de oportunidades y la actuación de los empleados públicos de un modo no discriminatorio- es legítimo y existe una relación de proporcionalidad entre éste y los medios utilizados ( $\$ 105$ y 106).

\subsection{Asuntos relativos a la filiación}

Junto con el reconocimiento jurídico de las relaciones estables de parejas del mismo sexo, en el ámbito familiar surgen controversias jurídicas relacionadas con la filiación. El TEDH ha resuelto varios asuntos en esta materia y en sus resoluciones se ve reflejada la evolución que se está produciendo desde hace unos años en los ordenamientos jurídicos de gran parte de los Estados miembros del CEDH en el sentido de reconocer las relaciones de filiación surgidas en las fami-

45 En el asunto Taddeucci c. Italia (recurso núm. 51362/09), los recurrentes, del mismo sexo, residían en Nueva Zelanda con el estatus de unión civil —regulado en la Civil Union Act 2004 para las parejas de diferente o del mismo sexo (bttp://www.legislation.govt.nz/act/public/2004/0102/ latest/DLM323385. btml, consultado el 06/03/2013) — y se trasladaron a Italia, país de origen de uno de ellos, donde las autoridades rechazaron conceder al otro, neozelandés, un permiso de residencia porque la legislación nacional sobre inmigración no permite obtenerlo a las parejas no casadas (bttp://budoc.echr.coe.int/sites/eng/pages/search.aspx?i=001-109591, consultado el 06/03/2013).

46 Según el art. 1(1) de la Civil Partnership Act 2004, una unión civil es una relación entre dos personas del mismo sexo (bttp://www.legislation.gov.uk/ukpga/2004/33/enacted, consultado el 27/02/2013). 
lias homoparentales (con dos progenitores del mismo sexo) y monoparentales en las que el progenitor no es heterosexual ${ }^{47}$.

En el caso Salgueiro da Silva Mouta c. Portugal, de 21 de diciembre de 1999, el conflicto surge en relación con la patria potestad sobre una niña cuyos progenitores pactaron, al divorciarse, que se otorgara a la madre, reservando un derecho de visita al padre. Los Tribunales atribuyeron la patria potestad a éste, por incumplir la madre el acuerdo, pero ésta recurrió y la Corte de apelación les devolvió a la situación anterior, introduciendo un elemento nuevo — que éste es homosexual y vive con otro hombre-, lo que supone, como observa el TEDH, una diferencia de trato basada en la orientación sexual (§ 28). El fin perseguido por la misma — proteger la salud y los derechos de la niña— es legítimo (§ 30); sin embargo, no cabe afirmar su razonabilidad, ya que del texto de la Sentencia recurrida se deduce que la homosexualidad del recurrente fue determinante para la decisión (§ 35). Por ello, el TEDH declara, por unanimidad, que ha habido violación del art. 8 CEDH combinado con el 14 (§ 36).

Nos centramos a continuación en el tema de la adopción por parte de personas homosexuales. En la STEDH X. y otros c. Austria, de 19 de febrero de 2013, que veremos más adelante, el Tribunal enumera las diferentes posibilidades. La primera es la adopción por una sola persona (adopción monoparental); la segunda, la adopción coparental, por la que una persona adopta al hijo de su pareja con el fin de que ambos tengan el estatuto de progenitor legal; y la tercera es la adopción conjunta por los dos miembros de la pareja (§ 100).

En materia de adopción monoparental por una persona homosexual, el TEDH ha resuelto dos casos. El primero es el de Fretté c. Francia, de 26 de febrero de 2002, quien tenía la intención de adoptar un menor de forma individual y, al mencionar su homosexualidad al inicio de los trámites, fue invitado a desistir. A pesar de destacar sus cualidades personales y educativas y las de su entorno, los diversos informes cuestionan si «sus particularidades, hombre soltero y homosexual, permiten confiarle un niño» (§ 10) y finalmente los servicios sociales rechazan su «solicitud de aprobación para la adopción» (demande d'agrément en vue d'adoption) alegando ausencia de referencia materna e indicando que no parece que su estilo de vida presente las garantías suficientes para acoger a un niño, en el plano familiar, educativo y psicológico (§ 11). El Tribunal administrativo manifestó que los motivos de rechazo son eufemismos para denegar su solicitud por ser

47 Sobre cómo regula el ordenamiento jurídico español las relaciones de filiación en el seno de estas familias puede verse Gilbaja CABrERo, Estela: «Orientación sexual y filiación. Especial referencia a la adopción», Revista General de Derecho Constitucional, núm. 17, 2013. 
soltero y homosexual ( $\$ \S 12$ y 13), pero su resolución fue anulada por el Consejo de Estado, momento en que el Sr. Fretté acude al TEDH.

El Tribunal recuerda que el Convenio no garantiza, como tal, un derecho a adoptar ${ }^{48}$. Además, el derecho al respeto de la vida familiar presupone la existencia de una familia y no protege el simple deseo de formar una ${ }^{49}$. En el caso en cuestión, el rechazo de la solicitud de aprobación para la adopción no puede considerarse en sí mismo contrario al derecho del recurrente al libre desarrollo de su personalidad o a su forma de vida. Sin embargo, teniendo en cuenta que el Derecho interno francés autoriza a toda persona soltera a solicitar una adopción ${ }^{50}$ y que al recurrente se le denegó su solicitud únicamente por su orientación sexual, concluye que ha habido una diferencia de trato fundada, de forma determinante, en esta circunstancia (\$ 32). El Tribunal considera el fin legítimo — proteger la salud y los derechos de los niños que pudieran estar presentes en un proceso de adopción ( $\$ 38)$ - y los medios proporcionales al mismo, teniendo en cuenta el margen de apreciación de los Estados y la necesidad de proteger el interés superior de los menores $(\$ \$ 40$ y 41) — protección que, según el Tribunal, aún no está clara en la comunidad científica en lo relativo a la acogida de un menor por una o dos personas homosexuales-. Por lo tanto, concluye, por cuatro votos contra tres, que no hay discriminación ${ }^{51}(\$ 43)$.

48 Decisión de la Comisión Europea de Derechos Humanos, asunto X c. Bélgica y Países Bajos, de 10 de julio de 1975: «el derecho a adoptar no figura, en tanto que tal, entre los derechos garantizados por el Convenio. No figura tampoco en el Pacto Internacional relativo a los derechos civiles y políticos (...). Para numerosos autores, no se trata, a la vista del Derecho interno, de un «derecho esencial análogo a una libertad individual»»; Decisión citada en la de 10 de julio de 1997, asunto Di Lazzaro c. Italia.

49 Así, en la STEDH Marckx c. Bélgica, de 13 de junio de 1979, § 31: «garantizando el derecho al respeto de la vida familiar, el art. 8 presupone la existencia de una familia»; citado en la STEDH Abdulaziz, Cabales y Balkandali c. Reino Unido, de 28 de mayo de 1985, § 62.

${ }^{50}$ Art. 343 CC francés: «la adopción puede ser solicitada por dos cónyuges no separados, casados desde hace más de dos años o que tengan ambos más de veintiocho años de edad»; art. 343-1: «la adopción puede ser también solicitada por toda persona de más de veintiocho años de edad (...)». (bttp://www.legifrance.gouv.fr/affichCode.do?cidTexte=LEGITEXT000006070721, consultado el 19/03/2013).

51 Siguen al fallo la opinión parcialmente concordante del Magistrado Costa, a la que se unen Jungwiert y Traja, y la parcialmente disidente de Nicolas Bratza, Fuhrmann y Tulkens. Los primeros señalan que los arts. 14 y $8 \mathrm{CEDH}$ no son aplicables al caso porque entienden que los hechos no se engloban en ninguna disposición del Convenio. Los segundos opinan que hubo discriminación, ya que el Estado francés, al autorizar por ley a las personas solteras a presentar una solicitud de adopción, adquiere una obligación positiva que le impide aplicar dicha ley de manera discriminatoria sin con ello violar el art. $14 \mathrm{CEDH}$. 
El siguiente asunto en el que nos detenemos es el de $\boldsymbol{E}$. B. $\boldsymbol{c}$. Francia, de 22 de enero de $2008^{52}$, cuya recurrente acude también al TEDH tras haberle sido denegada su solicitud individual de adopción. El Tribunal señala que el Convenio no garantiza ni el derecho de fundar una familia ni el derecho a adoptar, que el art. 8 presupone la existencia de una familia (\$ 41) y que la noción de «vida privada» es un concepto amplio que comprende, entre otros, el derecho a entablar y desarrollar relaciones con los semejantes ${ }^{53}$, al desarrollo personal ${ }^{54}$ y a la autodeterminación ${ }^{55}$, y engloba elementos como la identificación sexual, la orientación sexual y la vida sexual, que forman parte de la esfera personal protegida por el art. $8^{56}$, así como el derecho al respeto de la decisión de tener un hijo o de no tenerlo ${ }^{57}(\S 43)$. A continuación, subraya que el proceso litigioso no se refiere a la adopción de un menor en sí, sino al procedimiento de acceso a la misma, en el cual la recurrente afirma haber sido víctima de una discriminación, y recuerda que la protección del art. $14 \mathrm{CEDH}$ se extiende a los derechos adicionales que el Estado en cuestión haya decidido proteger, en este caso, el derecho de las personas solteras a solicitar una aprobación para la adopción (art. 343-1 CC), de modo que, en la aplicación de este precepto, el Estado francés no puede tomar medidas discriminatorias, pues ello vulneraría el Convenio ( $\S$ 47-49). El Tribunal constata que, aunque en las resoluciones administrativas se tuvo en cuenta la orientación sexual de la recurrente, ésta no fue decisiva. Sin embargo, le resulta significativo que esta circunstancia estuviera presente también en los informes previos, siendo determinante en algunos de ellos, de lo que deduce que fue decisiva para rechazar la solicitud de adopción,

52 Puede verse un comentario de esta Sentencia en Margénaud, Jean-Pierre: «Volte-face européenne sur le droit du célibataire homosexuel de pouvoir adopter». Revue trimestrielle de droit civil, abril-junio 2008, pp. 249-252.

53 STEDH Niemietz c. Allemania, de 16 de diciembre de 1992, § 29: «el respeto a la vida privada debe también comprender en cierto grado el derecho a establecer y desarrollar relaciones con otros seres humanos».

${ }^{54}$ STEDH Bensaïd c. Reino Unido, de 6 de febrero de 2001, § 47: «el art. 8 protege el derecho a la identidad y al desarrollo personal».

55 STEDH Pretty c. Reino Unido, de 29 de abril de 2002, § 61: «aunque ningún caso previo ha establecido que un derecho a la autodeterminación esté contenido en art. 8 del Convenio, el TEDH considera que la noción de autonomía personal es un principio importante para la interpretación de sus garantías».

56 SSTEDH Dudgeon c. Reino Unido, de 22 de octubre de 1981, § 41: «el derecho del recurrente al respeto de su vida privada (que incluye su vida sexual)»; y Laskey, Jaggard y Brown c. Reino Unido, de 19 de febrero de 1997, § 36: «no puede haber duda de que la orientación y la actividad sexuales son aspectos íntimos de la vida privada».

57 STEDH Evans c. Reino Unido, de 10 de abril de 2007, § 71: «el art. 8 (...) incluye el derecho al respeto a las decisiones de devenir y no devenir progenitor». 
declarando, por diez votos contra siete, que ha habido violación del art. 14 CEDH combinado con el art. $8^{58}$ ( $\$$ 81-98).

En relación con la adopción coparental, el TEDH ha resuelto por el momento dos asuntos. El primero, Gas y Dubois c. Francia, de 15 de marzo de 2012, da respuesta al recurso de dos mujeres unidas por un PACS. La Sra. Dubois, en el año 2000, había dado a luz a una niña concebida en Bélgica por reproducción asistida, que fue inscrita en el Registro civil y reconocida por su madre biológica — conforme a la ley belga, la filiación respecto del padre (donante anónimo) no quedó establecida- Cuando la Sra. Gas formuló una solicitud de adopción simple $\mathrm{e}^{59} \mathrm{de}$ la hija de su compañera, a pesar de constatarse que se cumplían las condiciones legales de la adopción y que las recurrentes se ocupaban activa y conjuntamente de la niña, se le denegó alegando que la autoridad parental ${ }^{60}$ quedaría transferida totalmente a la adoptante, perdiéndola la madre biológica. Tras varias resoluciones

${ }^{58}$ Se emitieron cuatro opiniones disidentes y una concordante. El Magistrado Costa, al que se unen Türmen, Ugrekhelidze y Jočienè, considera que no hubo violación del CEDH porque no deduce del expediente que la homosexualidad fuera decisiva para denegar la solicitud de adopción. Zupančič cree que, en atención a los hechos — principalmente a la actitud indiferente de la compañera de la madre hacia la adopción- y al interés superior del menor, no puede decirse que se haya violado el CEDH. Lorenzen y Jebens señalan, en su opinión concordante, que están de acuerdo en que hubo discriminación porque la orientación sexual fue decisiva, pero que corresponde a los Tribunales franceses la decisión sobre el fondo. Por su parte, Loucaides niega la violación del $\mathrm{CEDH}$, pues opina que, para decidir sobre el interés del menor, las autoridades pueden legítimamente tener presente la orientación sexual y el modo de vida de la recurrente, en especial la actitud de su compañera y añade que, aunque los homosexuales tienen derecho a no ser discriminados por su orientación sexual, deben «como cualquier otra persona que presenta una particularidad, aceptar que es probable que no puedan realizar ciertas actividades que, por su naturaleza y en determinadas circunstancias, no concilia con su modo de vida o particularidad». Mularoni no comparte la opinión de la mayoría en cuanto a la admisibilidad, el razonamiento y la conclusión, afirmando que la actitud de la compañera es razón suficiente para rechazar la solicitud de adopción y que las autoridades francesas precisaron que la homosexualidad de la recurrente no fue la causa de la decisión.

59 En Francia existen dos tipos de adopción: plena y simple. La adopción plena sólo puede constituirse durante la minoría de edad del adoptado, puede ser solicitada por un matrimonio o por una sola persona y confiere al adoptado una filiación que sustituye a la de origen ( $§ 18$; arts. 343-350 CC francés). La adopción simple no rompe el vínculo entre el adoptado y su familia de origen, creando una filiación suplementaria; si el adoptado es menor (puede no serlo), el adoptante adquiere todos los derechos de autoridad parental, salvo cuando el adoptante es el cónyuge del padre o de la madre, caso en que aquélla es compartida entre ambos cónyuges (arts. 360-362 CC francés, bttp://www. legifrance.gouv. frlaffichCode.do? cidT exte=LEGITEXT000006070721, consultado el 21/12/2013).

${ }^{60} \mathrm{La}$ autoridad parental es un conjunto de derechos y deberes que protegen el interés del menor (art. 371-1 CC francés, http://www.legifrance.gouv. fr/affichCode.do? cidTexte=LEGITE XT000006070721, consultado el 8/11/2012). 
desestimatorias, las Sras. Gas y Dubois acuden al TEDH al apreciar una discriminación entre las parejas homosexuales y las heterosexuales, puesto que aquéllas no pueden —en ese momento- contraer matrimonio y así beneficiarse del art. 365 $\mathrm{CC}^{61}$. El Tribunal constata la presencia de una «vida familiar» ( $\$ 37$ ), pero no encuentra distinción discriminatoria en relación con las parejas casadas, pues no considera que se trate de situaciones jurídicas comparables, ya que el matrimonio confiere un estatuto particular a quienes lo contraen ${ }^{62}$. Tampoco aprecia diferencia de trato fundada en la orientación sexual en relación con las parejas heterosexuales no casadas, hayan o no firmado un PACS, puesto que a éstas también se les denegaría la adopción simple (\$§ 65-69). Al sostener que no existe diferencia de trato, descarta la discriminación y concluye, por seis votos contra uno, que no ha habido violación del art. $14 \mathrm{CEDH}$ combinado con el art. $8^{63}$.

El supuesto de hecho que da lugar a la recién comentada Sentencia guarda similitud con el del asunto X. y otros c. Austria, de 19 de febrero de $2013^{64}$. Se

${ }^{61} \mathrm{El}$ art. 365 CC francés dispone que los derechos de autoridad parental recaen únicamente sobre la persona del adoptante, a menos que sea el cónyuge del padre o de la madre del adoptado, en cuyo caso el adoptante tiene la autoridad parental de forma conjunta con su cónyuge, el cual conserva la totalidad de su ejercicio, salvo declaración conjunta de ambos cónyuges para un ejercicio compartido (bttp://www. legifrance.gouv. frlaffichCode.do? cidT exte=LEGITEXT000006070721, consultado el 12/03/2013).

${ }^{62}$ En este sentido, la Decisión del TEDH Lindsay c. Reino Unido, de 11 de noviembre de 1986, dice que «aunque en algunos campos la relación de hecho de personas que conviven está hoy en día reconocida, todavía existen diferencias entre las parejas casadas y las no casadas, en particular, diferencias en el estatus legal y los efectos legales. El matrimonio continúa estando caracterizado por un corpus de derechos y obligaciones que lo diferencian sustancialmente de la situación de un hombre y una mujer que conviven», afirmación que reitera la Decisión Nylund c. Finlandia, de 29 de junio de 1999. En la Decisión Shackell c. Reino Unido, de 27 de abril de 2000, «el Tribunal acepta que puede haber una creciente aceptación social de las relaciones estables fuera de la noción tradicional del matrimonio. Sin embargo, el matrimonio sigue siendo una institución ampliamente aceptada en el sentido de que confiere un estatus particular a quienes lo contraen». Finalmente, afirma en la STEDH Burden c. Reino Unido, de 29 de abril de 2008, $\$ 63$, que «el matrimonio confiere un estatus especial a quienes lo contraen», citada en la Decisión Serife Yigit c. Turquía, de 2 de noviembre de 2010. El asunto Burden c. Reino Unido, de 29 de abril de 2008, ha sido reseñado por BouAzZA AriÑo, Omar: «Tribunal Europeo de Derechos Humanos», Revista General de Derecho Administrativo, núm. 14/2007.

${ }^{63}$ Resulta de especial interés la opinión disidente del Magistrado Villiger, quien se opone a la perspectiva adoptada por la Sentencia, la cual entiende que debería haberse centrado en el menor, analizando la diferencia de trato entre los hijos de una pareja heterosexual, que se benefician de la autoridad parental compartida, y los de una pareja homosexual, donde la adopción está excluida. Esta diferencia de trato es, a su juicio, contraria al art. $14 \mathrm{CEDH}$ combinado con el 8, pues carece de justificación.

${ }^{64}$ No obstante, el Tribunal aprecia una diferencia crucial: el Derecho francés reserva la adopción coparental a las parejas casadas; el asunto que toma como análogo es Karner c. Austria, de 24 
trata también de una pareja de mujeres en la que una de ellas trata de adoptar al hijo engendrado por la otra ${ }^{65}$, con el cual conviven y del que se ocupan conjuntamente. El Tribunal competente se opuso, invocando el art. 182(2) CC, que dispone que en los casos de adopción individual se rompe el vínculo jurídico con el progenitor biológico del mismo sexo que el adoptante, persistiendo con el de distinto ( $\$ 27)$. Tras varios recursos, acuden al TEDH, el cual descarta la discriminación en relación con los matrimonios al no considerar su situación comparable ${ }^{66}$. Sí es comparable con la de una pareja heterosexual no casada en la que uno de sus miembros tenga la intención de adoptar al hijo del otro. Según el ordenamiento austriaco, es posible la adopción coparental en el seno de una pareja heterosexual sin que se rompa el vínculo jurídico entre el hijo y el progenitor biológico, lo cual es imposible para las parejas homosexuales, teniendo en cuenta el citado art. 182(2) CC y el art. 8(4) de la Ley de Parejas Registradas — solamente para parejas del mismo sexo_-, que establece que uno de los miembros de la pareja no puede adoptar al hijo del otro. De todo ello deduce el TEDH una diferencia de trato fundada en la orientación sexual (\$ 130). Los fines de la medida - preservar la «familia tradicional» ${ }^{67}$ y el interés del menor- los considera legítimos ( $\$ 137$ y 138), pero aprecia «serias dudas» en lo relativo a la proporcionalidad, teniendo en cuenta la existencia de la familia de hecho, la importancia

de julio de 2003, en el que la legislación denegaba a las parejas homosexuales un derecho reconocido a las heterosexuales no casadas.

${ }_{65}$ En este caso el padre sí es conocido, aunque la madre ostenta en exclusiva la patria potestad.

${ }^{66}$ El Código Civil austriaco prevé un régimen de adopción específico para las parejas casadas - exclusivamente las heterosexuales_ y la no apertura del matrimonio a las parejas del mismo sexo es compatible con el CEDH $(\$ \S 106-110)$.

67 Según la jurisprudencia del TEDH (SSTEDH Karner c. Austria, de 24 de julio de 2003, $\S 41 ;$ y Kozak c. Polonia, de 2 de marzo de 2010, $§ 98$ y 99), el objetivo consistente en proteger la «familia tradicional» es abstracto y admite una gran variedad de medidas. Además, a la vista de que el Convenio es «un instrumento vivo que debe interpretarse a la luz de las condiciones actuales», el Estado debe elegir las medidas para proteger la familia y garantizar el respeto a la vida familiar teniendo en cuenta la evolución de la sociedad. Y, cuando el margen de apreciación de los Estados es estrecho, como en el caso de la diferencia de trato fundada en el sexo o en la orientación sexual, el principio de proporcionalidad no exige solamente que la medida tomada sea normalmente susceptible de permitir la realización del fin perseguido, sino que es obligado demostrar que era necesario, para atender a ese fin, excluir a ciertas personas —en este caso aquéllas que tienen una relación homosexual— del campo de aplicación de la medida. En virtud de esta jurisprudencia, la carga de esta prueba incumbe al Gobierno. En este caso, el Gobierno austriaco debe demostrar que la protección de la familia tradicional y, más en concreto, la protección del interés del menor, exige prohibir a las parejas homosexuales la adopción coparental, abierta a las parejas heterosexuales no casadas; pero el Gobierno no presenta ningún elemento de prueba susceptible de demostrar que las familias homoparentales no pueden en ningún caso ocuparse adecuadamente de un niño (X. y otros c. Austria, de 19 de febrero de 2013, §§ 139-142). 
de su reconocimiento jurídico, la incapacidad del Gobierno de probar que sería perjudicial para un niño ser criado por una pareja homosexual o tener legalmente dos padres o dos madres y, sobre todo, el hecho de que el ordenamiento autorice la adopción por una sola persona y se refiera a la exigencia de consentimiento de su cónyuge o pareja registrada ${ }^{68}$. Además, el interés superior del menor debería poder examinarse por los Tribunales caso por caso ( $\$ 143-146)$.

El Tribunal recuerda que en el caso de que se alegue discriminación fundada en el sexo o en la orientación sexual, el margen de apreciación de los Estados es estrecho, aunque en general sea amplio en cuestiones en las que no hay consenso, como ocurre en lo relativo a la adopción coparental por parte de las parejas homosexuales - hasta el momento sólo prevista en seis Estados miembros-. Además, son escasas las ratificaciones al Convenio europeo en materia de adopción de menores ${ }^{69}$, de 2008, que reconoce la libertad de los Estados para permitir la adopción por parte de las parejas homosexuales ${ }^{70}$; no obstante, ello no implica, como indica el Tribunal, que sean libres de tratar de forma diferente a las parejas estables heterosexuales y a las homosexuales ${ }^{71}$. Teniendo en cuenta todo lo

${ }^{68}$ Art. 181(1) CC austriaco, en su redacción dada por la Ley de Parejas Registradas: «la adopción sólo se autorizará cuando estén de acuerdo las siguientes personas: (...) el cónyuge o pareja registrada del adoptante» (bttp://www.ris.bka.gv.at/Dokumente/Bundesnormen/NOR40112783/ NOR40112783. html, consultado el 15/03/2013). El contraste de este precepto con el que impide la adopción del hijo del compañero del mismo sexo lleva al Tribunal a afirmar que «el Derecho austriaco parece carecer de coherencia».

69 De los 49 Estados a cuya firma se encuentra abierto el Convenio europeo en materia de adopción de menores, lo han firmado quince y ratificado siete (Dinamarca, España, Finlandia, Noruega, Países Bajos, Rumanía y Ucrania). http://conventions.coe.int/Treaty/Commun/ChercheSig.asp ?NT $=202 E C M=1 E D F=16 / 03 / 2013 \mathcal{E} C L=E N G$, consultado el 07/01/2014.

70 Art. 7 European Convention on the Adoption of Children (Revised), Strasbourg, 27. XI.2008: «Condiciones para la adopción / 1. La Ley debe permitir que un niño sea adoptado: a) por dos personas de diferente sexo casadas entre ellas o registradas como pareja (cuando exista tal institución); b) por una persona. / 2. Los Estados son libres para extender la aplicación de este Convenio a las parejas del mismo sexo que estén casadas o registradas como pareja. También son libres para extenderla a las parejas de diferente sexo y las parejas del mismo sexo que convivan en una relación estable». http://conventions.coe.int/Treaty/en/Treaties/Html/202.btm, consultado el 16/03/2013.

${ }^{71}$ En este sentido, la Recomendación CM/Rec(2010)5, de 31 de marzo de 2010 [Recommendation CM/Rec(2010)5 of the Committee of Ministers to member states on measures to combat discrimination on grounds of sexual orientation or gender identity (Adopted by the Committee of Ministers on 31 March 2010 at the 1081 st meeting of the Ministers' Deputies)], dispone en su párrafo 23 que «donde la legislación nacional confiera derechos y obligaciones a las parejas no casadas, los Estados miembros deben asegurarse de que se aplica de una forma no discriminatoria a las parejas del mismo sexo y a las de sexo diferente, incluyendo el respeto a los beneficios relacionados con la pensión del superviviente y los derechos de posesión» (bttps://wcd.coe.int/ViewDoc.jsp? id=1606669, consultado el 16/03/2013). 
anterior, el TEDH estima que el Gobierno no aporta razones particularmente sólidas que den a entender que la exclusión de las parejas homosexuales de la adopción coparental abierta a las parejas heterosexuales no casadas sea necesaria para la preservación de la familia tradicional o la protección de los intereses del menor. Por tanto, declara, por diez votos contra siete, que ha habido violación del art. $14 \mathrm{CEDH}$ combinado con el art. $8^{72}$.

En esta materia hay una Decisión del TEDH, además de dos casos pendientes. En el caso Boeckel y Gessner-Boeckel c. Alemania (Decisión de 7 de mayo de 2013), el recurso fue interpuesto por dos mujeres que forman una pareja registrada. Cuando la Sra. Gessner-Boeckel dio a luz, en el certificado de nacimiento se la inscribió como madre, quedando en blanco la referencia al padre. Un mes después, de acuerdo con el art. $9 \S 7$ de la Ley de Parejas Registradas ${ }^{73}$, la Sra. Boeckel adoptó al niño, el cual adquirió la posición legal de hijo de ambas. Posteriormente, solicitaron que se modificara el certificado de nacimiento inscribiendo a la Sra. Boeckel como segundo progenitor, lo que les fue denegado. Ante el TEDH, afirman haber sufrido la vulneración del art. 14 CEDH combinado con el 8 y alegan la desprotección en que se encontraba el hijo en el periodo anterior a su adopción, cuando carecía de relación jurídica con una de sus madres. El Tribunal considera que la situación de las recurrentes no es comparable a la de una pareja casada de diferente sexo, descartando la vulneración del art. $14 \mathrm{CEDH}$, y tampoco aprecia la del art. $8 \mathrm{CEDH}$, puesto que la presunción de paternidad que se da en el matrimonio no puede darse, por razones biológicas, en las parejas del mismo sexo ${ }^{74}$. Por tanto, el recurso resulta inadmitido.

72 El Magistrado Spielmann indica en su opinión concordante que no era necesario comparar la situación de las recurrentes con la de una pareja casada. Por su parte, Casadevall, Ziemele, Kovler, Jočienè, Šikuta, de Gaetano y Sicilianos emitieron una opinión parcialmente disidente conjunta afirmando que no hubo violación del art. $14 \mathrm{CEDH}$ combinado con el 8 porque, a su juicio, el precepto aplicado no distingue según la orientación sexual de los adoptantes y que la sustitución de su padre por la compañera de su madre no respondería al interés del menor. Además, no están de acuerdo con la interpretación que se hace del Convenio europeo en materia de adopción de menores y de la Recomendación CM/Rec(2010)5 y estiman que el Tribunal ha sobrepasado los límites del método de interpretación evolutiva, la cual tiene por fin acompañar y canalizar los cambios, no precederlos y mucho menos tratar de imponerlos.

${ }^{73}$ Según el art. $9 \S 7$ de la Ley de Parejas Registradas, uno de los miembros de la pareja puede adoptar al hijo de su compañero, en cuyo caso se aplican mutatis mutandis las disposiciones del Código Civil referentes a la adopción (bttp://www.gesetze-im-internet.delenglisch_lpartg/englisch_ lpartg.html\#p0039; http://www.gesetze-im-internet.de/englisch_bgb/, consultado el 08/01/2013).

${ }^{74}$ El ordenamiento español sí permite determinar la filiación respecto de dos mujeres desde el momento del nacimiento (arts. 148 Ley de 8 de junio de 1957, sobre el Registro Civil -desde su modificación por la Ley 13/2005- y 3.7 Ley 14/2006, de 26 de mayo, sobre técnicas de reproducción humana asistida). 
Por otro lado, se encuentran pendientes de resolución los asuntos Hallier y Lucas c. Francia (recurso núm. 46386/10) y Bonnaud y Lecoq c. Francia (recurso núm. 6190/11). En el primero, se denegó a una mujer la baja de maternidad tras dar a luz su compañera; en el segundo, una pareja de mujeres, cada una de las cuales tuvo un hijo mediante reproducción asistida, vieron denegada su solicitud de establecer la autoridad parental de cada una de ellas respecto del hijo de su compañera.

\section{OTROS ASUNTOS RELEVANTES}

Comentamos a continuación, de forma más breve, otras Sentencias del TEDH relacionadas con los derechos de las personas homosexuales en ámbitos diferentes a los tratados.

En los últimos años, el TEDH ha conocido de varios asuntos relativos a los derechos reconocidos en el art. $11 \mathrm{CEDH}^{75}$ en relación con la orientación sexual, como el de Bączkowski y otros c. Polonia, de 3 de mayo de $2007^{76}$, a cuyos recurrentes se les denegó la autorización para celebrar una manifestación que tenía por objetivo concienciar a la opinión pública sobre la discriminación contra diversos grupos, entre ellos las minorías sexuales. El Tribunal declara, por unanimidad, la violación del art. $11 \mathrm{CEDH}$, individualmente y combinado con el art. 14, ya que tal denegación constituye una injerencia desproporcionada en la libertad de reunión, teniendo en cuenta que el Estado no tiene un mero deber de no interferir en el ejercicio del derecho, sino obligaciones positivas para garantizar su ejercicio ${ }^{77}$.

Son muy similares los hechos que dan lugar a las Sentencias Alekseyev c. Rusia $^{78}$, de 21 de octubre de 2010, y Genderdoc-M c. Moldavia, de 12 de junio

${ }^{75} \mathrm{El}$ art. $11 \mathrm{CEDH}$ reconoce a toda persona el derecho a la libertad de reunión pacífica y a la libertad de asociación, y señala que «el ejercicio de estos derechos no podrá ser objeto de otras restricciones que aquellas que, previstas por la ley, constituyan medidas necesarias, en una sociedad democrática (...)».

${ }^{76}$ Un análisis más extenso de esta Sentencia puede verse en Van Der Bogaert, Sina: «ECHR Rules on Illegal Ban of Warsaw Equality Parade: The Case of Baczkowski and Others v. Poland», German Law Journal, vol. 8, núm. 9, 2007, pp. 889-902.

77 Además, se declaró vulnerado el art. 11 combinado con el 13 porque la resolución que dictaminó que la prohibición vulneraba el derecho llegó después de la fecha fijada para el acto.

${ }^{78}$ Sobre la situación de los derechos de las personas LGTB en Rusia, puede verse: SHABANOVA, Maria: «Rights of LGBT Minority in Russian Law and Practice», Russia and the EU Uneasy Relations. A Look From Belgium. Academic Papers of the 9th International Session of the HSE Russian - European Centre for Multidisciplinary Research, Brujas, 2009, pp. 190-195. 
de 2012, en las que el Tribunal declara la violación de los arts. 11 CEDH, 13 combinado con el 11, y 14 combinado con el 11 (por unanimidad salvo respecto a la vulneración de los arts. 11 y $14 \mathrm{CEDH}$ en el asunto Genderdoc- $M c$. Moldavia).

En cuanto a los límites de la libertad de expresión en relación con la protección de la reputación y de los derechos ajenos ${ }^{79}$, concretamente los de las personas homosexuales, puede citarse la STEDH Vejdeland y otros c. Suecia, de 9 de febrero de 2012. Los recurrentes, condenados por el delito de «agitación contra un grupo nacional o étnico» ${ }^{80}$ tras distribuir en una escuela de secundaria unos folletos ofensivos contra los homosexuales, acudieron al TEDH por entender violado su derecho a la libertad de expresión. El Tribunal declara, por unanimidad, la no violación de tal derecho, ya que la injerencia está prevista por la Ley, persigue un fin legítimo - la protección de la reputación y de los derechos ajenos_- ( $\$ 49)$, es proporcional al mismo y puede calificarse de «necesaria en una sociedad democrática» (§ 59). En opinión del TEDH, aunque las declaraciones contenidas en los folletos ${ }^{81}$ no incitan directamente a cometer actos de odio, son acusaciones graves y perjudiciales ( $\$ 54)$. Asimismo, recuerda que la incitación al odio no implica necesariamente la llamada a un acto de violencia u otros actos criminales; insultar, ridiculizar o calumniar a grupos específicos de la población puede ser suficiente para que las autoridades combatan la libertad de expresión ejercida de modo irresponsable ${ }^{82}$, y añade que los discursos políticos que incitan al odio basado en prejuicios religiosos, étnicos o culturales representan un peligro para la paz social y la estabilidad política en los Estados democráticos (§ 73). Además, subraya que la discriminación basada en la orientación sexual es igual de seria que la basada en la raza, el origen o el $\operatorname{color}^{83}(§ 55)$.

$79 \mathrm{El}$ art. $10 \mathrm{CEDH}$ reconoce a toda persona el derecho a la libertad de expresión, el cual «podrá ser sometido a ciertas formalidades, condiciones, restricciones o sanciones, previstas por la ley, que constituyan medidas necesarias, en una sociedad democrática (...)».

${ }^{80} \mathrm{El}$ art. 8, capítulo 6 del Código Penal de Suecia tipifica como delito de «agitación contra un grupo nacional o étnico» los casos en que una persona, en un comunicado difundido, amenaza o expresa desprecio hacia un grupo nacional, étnico u otro grupo de personas con alusión a la raza, color, origen nacional o étnico, creencias religiosas u orientación sexual (Vejdeland y otros $c$. Suecia, § 18).

${ }^{81}$ En ellos se dice, entre otras cosas, que la homosexualidad es una «tendencia sexual desviada» que tiene un efecto moralmente destructivo en la sociedad, que es una de las principales razones de la expansión del SIDA y que el «lobby homosexual» trata de restar importancia a la pedofilia ( $(8)$.

${ }^{82}$ En este sentido, la STEDH Féret c. Bélgica, de 16 de julio de 2009, en relación con el racismo.

83 Así, entre otras, la STEDH Smith y Grady c. Reino Unido, de 27 de septiembre de 1999, § 97. 
Parecidas circunstancias originaron el asunto Fairfield y otros c. Reino Unido, inadmitido por Decisión del TEDH de 8 de marzo de 2005, cuyos recurrentes consideran restringida su libertad de expresión al ser sancionados por portar carteles con lemas ofensivos contra los homosexuales.

En relación con la libertad de expresión hay varios casos pendientes. Uno de ellos es el de Zhdanov y Rainbow House c. Rusia (recurso núm. 12200/08), planteado después de que las autoridades rusas denegaran el registro de la asociación «Rainbow House», que tiene como fin la defensa de los derechos de los gays, lesbianas, bisexuales y transexuales. La denegación se funda en la afirmación de que las actividades de la asociación vulnerarían los intereses de los ciudadanos con una orientación sexual tradicional, los de la sociedad en su conjunto y los del Estado, destruyendo los valores morales y quebrantando la soberanía y la integridad territorial de la Federación Rusa mediante el decrecimiento de su población; pondrían en peligro las instituciones de la familia y el matrimonio y fomentarían el odio y el enfrentamiento social y religioso, provocando una respuesta violenta. Asimismo, señalan las autoridades que los fines de la asociación no sólo implican la protección de los derechos e intereses de los ciudadanos con una orientación sexual no tradicional, sino que también trata de incrementar el número de éstos, convirtiendo a quienes sin esa propaganda tendrían una orientación tradicional. Además, consideran que la expresión «orientación sexual no tradicional» es amplia y puede englobar la pedofilia; que cualquier injerencia en la vida privada, incluyendo la dirigida a su protección, es contraria a la Constitución; y que la ayuda a personas que sufren VIH/SIDA, proclamada como uno de los fines de la asociación, podría violar sus derechos a la confidencialidad y al respeto de la vida privada. Por todo ello, se califica la asociación de extremista, lo que tuvo entre sus consecuencias el registro policial del domicilio de uno de sus miembros para iniciar un proceso penal por pertenencia a organización extremista. Las cuestiones que se le plantean al TEDH son si la denegación de registro vulnera los arts. 11 y $14 \mathrm{CEDH}$, constituyendo una discriminación basada en la orientación sexual, y los arts. 6 y $13 \mathrm{CEDH}$ por haber aplicado injustamente el Derecho interno.

También contra Rusia se han presentado tres recursos, relacionados con la prohibición de la «propaganda de la homosexualidad» ${ }^{84}$ dirigida a menores, en un primer momento en varias leyes regionales y finalmente en la Ley Federal

${ }^{84}$ Sobre la «propaganda de la homosexualidad» en Rusia, puede verse el artículo de Johnson, Paul: «'Homosexual propaganda' laws in the Russian Federation: are they in violation of the European Convention on Human Rights?» (bttp://papers.ssrn.com/sol3/papers.cfm?abstract_ $i d=2251005$, consultado el 23/06/2014). 
135-FZ, de 29 de junio de $2013^{85}$. Los asuntos Bayev c. Rusia (recurso núm. 67667/09), Kiselev c. Rusia (recurso núm. 44092/12) y Alekseyev c. Rusia (recurso núm. 56717/12) tienen como recurrentes a varios activistas que exhibieron carteles en defensa de los derechos de los homosexuales delante de colegios y fueron arrestados y multados en aplicación de las citadas leyes. Alegan ante el TEDH la vulneración del art. $10 \mathrm{CEDH}$, considerado individualmente y combinado con el art. 14 .

Por otra parte, el Tribunal ha resuelto varios casos de malos tratos sufridos por presos homosexuales, como el de Stasi c. Francia, de 20 de octubre de 2011 , cuyo recurrente denuncia malos tratos por parte de otros presos. El Tribunal concluye que el Derecho interno le aseguró una protección efectiva y suficiente contra los ataques a su integridad física y que las autoridades penitenciarias tomaron las medidas necesarias para protegerlo, por lo que declara, por cinco votos contra dos, la no violación del art. $3 \mathrm{CEDH}^{86}$ (§ 102).

En el caso X. c. Turquía, de 9 de octubre de 2012, el recurrente también denunció ser víctima de intimidación y acoso por parte de otros presos a causa de su homosexualidad. Tras solicitar ser trasladado a una celda colectiva con otros homosexuales, fue enviado, durante ocho meses y medio, a una individual en muy malas condiciones y aislado del resto de reclusos, lo que le causó problemas psiquiátricos. La administración penitenciaria basa su decisión en que el recurrente corría el riesgo de sufrir ataques contra su integridad; pero el TEDH considera que, aunque eran temores fundados, ello no justifica una medida de exclusión total de la colectividad carcelaria y de salir al aire libre, por lo que concluye que las condiciones de detención del recurrente, agravadas por la ausencia de un recurso efectivo, pueden entenderse como un trato inhumano o degradante infligido en violación del art. $3 \mathrm{CEDH}$, lo que declara por unanimidad. ( $\S 37-51)$. Asimismo declara, por seis votos contra uno, la vulneración del art. $14 \mathrm{CEDH}$ combinado con el 3, ya que la orientación sexual del recurrente fue la principal razón de la medida tomada y ésta no es proporcional al fin que se dijo buscar: la seguridad de aquél.

${ }^{85}$ La Ley Federal 135-FZ, de 29 de junio de 2013, modifica la Ley federal para la protección de los niños de la información que daña su salud y desarrollo y otras leyes de la Federación dirigidas a la protección de la infancia de información contraria a los valores familiares tradicionales. Puede verse una traducción al inglés en http://www.threefold.ru/russian-laws-amended-federal-law-no-135-fzamending-certain-laws-russian-federation-view-protect-children (consultado el 11/01/2014).

${ }^{86}$ En su opinión disidente conjunta, los Magistrados Spielmann y Nußberger explican que, a su entender, sí hubo violación del art. $3 \mathrm{CEDH}$ (que prohíbe la tortura y los tratos o penas inhumanos o degradantes) porque las autoridades penitenciarias no tomaron las medidas necesarias para proteger al recurrente de la violencia ejercida contra él por otros presos. 
Por último, hacemos referencia al asunto M. K. N. c. Suecia, de 27 de junio de 2013. Se trata de un iraquí que presentó una solicitud de asilo en Suecia afirmando ser perseguido en su país por ser cristiano. Avanzado el procedimiento, añadió a sus declaraciones que también corría riesgo de persecución por haber tenido una relación homosexual y que habían asesinado a su compañero. Las autoridades suecas rechazaron su solicitud. El TEDH recuerda que, aunque los Estados tienen derecho a controlar la entrada, residencia y expulsión de extranjeros, serán responsables de una violación del art. $3 \mathrm{CEDH}$ si hay pruebas sustanciales de que la expulsión de una persona la sitúa en un riesgo real de ser sometida en el país receptor a tratos contrarios al citado artículo (§ 25). Tras analizar la situación general en Irak, la de los cristianos en ese país y en la región del Kurdistán, y las particulares circunstancias del recurrente, el TEDH declara, por cinco votos frente a dos, que su deportación no implica riesgo de violación del art. $3 \mathrm{CEDH}$, puesto que los cristianos sufren persecución en el sur y el centro del país pero no en el Kurdistán, donde podría ser realojado (\$ 44). En cuanto a la orientación sexual que alega el recurrente, aunque los homosexuales se encuentran en una situación difícil también en el Kurdistán, es irrelevante para la decisión puesto que aquél manifestó su intención de vivir con su mujer e hijos y su relato carece de credibilidad ( $\$ 43$ ). No obstante, el Tribunal decide por unanimidad indicar al Gobierno de Suecia que no deporte al recurrente hasta que la Sentencia sea firme o hasta nueva orden.

\section{CONCLUSIONES}

A lo largo de este trabajo se ha expuesto cómo ha evolucionado en los últimos años el reconocimiento de los derechos de las personas homosexuales en el ámbito de aplicación del Convenio Europeo de Derechos Humanos. Se han visto en primer lugar las Sentencias relativas a la despenalización de la homosexualidad, continuando con las referidas al reconocimiento jurídico de la vida familiar de las parejas del mismo sexo, y acabando con varios asuntos en los que el derecho a no ser discriminado por la orientación sexual concurre con otros como el derecho de reunión, la libertad de expresión y la prohibición de la tortura y los tratos inhumanos o degradantes.

Volviendo al punto de partida y a fin de dibujar la evolución de la jurisprudencia del TEDH en materia de orientación sexual, extraemos lo esencial de todo lo dicho.

Así, del primer grupo de Sentencias puede destacarse que ni la pretendida protección de la moral y los derechos y libertades de los demás, ni la existencia 
de una opinión pública favorable a la prohibición penal de la homosexualidad son suficientes para justificar la misma. Se trata en todo caso de una medida que vulnera el derecho a la vida privada. Además, las diferencias de trato basadas en la orientación sexual no se justifican sino con la existencia de razones especialmente serias.

Por otro lado, cuando se trata de analizar si existe una discriminación basada en la orientación sexual, para que se cumpla el principio de proporcionalidad se requiere, además de que la medida en cuestión sirva para alcanzar el fin perseguido, que éste no se pueda conseguir sin excluir a una categoría de personas, en concreto a las homosexuales.

Asimismo, queda reconocida en la jurisprudencia del TEDH la vida familiar de las parejas estables del mismo sexo, las cuales necesitan reconocimiento y protección legales, para lo cual los Estados gozan de un margen de apreciación en cuanto a la apertura del matrimonio.

En cuanto a los asuntos relativos a la filiación, para su resolución el Tribunal aplica el test de proporcionalidad partiendo de que el CEDH no reconoce como tal un derecho a adoptar y que el derecho al respeto a la vida familiar presupone la existencia de una familia. Fijado lo dicho, analiza cada caso teniendo en cuenta, por una parte, que en materia de matrimonio y adopción por parejas homosexuales no hay consenso a nivel europeo, por lo que reconoce cierto margen de apreciación a los Estados y, por otra, que tal margen es estrecho cuando se alega discriminación basada en la orientación sexual. Asimismo, son de gran relevancia para el fallo tanto los detalles de los expedientes como la legislación aplicable. En este grupo de Sentencias puede apreciarse una notable evolución en la posición del TEDH, a pesar de la corta distancia en el tiempo entre ellas, como puede verse al comparar los asuntos Fretté c. Francia, de 26 de febrero de 2002, y E. B. c. Francia, de 22 de enero de 2008. En ambos la legislación aplicable es la misma, y el Tribunal constata que la orientación sexual fue determinante para rechazar la solicitud de adopción. Ahora bien, mientras que en el asunto Fretté c. Francia el Tribunal considera que tal rechazo está amparado por el margen de apreciación de los Estados, en la más reciente Sentencia E. B. c. Francia, la diferencia de trato basada en la orientación sexual es suficiente para declarar que hubo discriminación.

A la vista de la evolución reseñada, y en especial tras observar las Sentencias más recientes relativas a la adopción, me aventuro a prever que, en consonancia con el creciente número de ordenamientos que otorgan reconocimiento jurídico a las parejas del mismo sexo en igualdad de condiciones con las heterosexuales, llegará un momento, tal vez próximo, en que el Tribunal afirme que ya no puede apelarse al margen de apreciación de los Estados en esta materia y que el art. 
$14 \mathrm{CEDH}$ debe interpretarse entendiendo que, en el reconocimiento jurídico de las parejas estables, no cabe ninguna distinción basada en la orientación sexual. Es decir, que una regulación en la que se prevean diferentes instituciones por razón de la orientación sexual, o distintos grados en la misma institución dependiendo de tal circunstancia, como lo que disponen actualmente algunos ordenamientos respecto a la adopción, será discriminatoria y, por tanto, contraria al Convenio Europeo de Derechos Humanos.

No obstante, como se aprecia especialmente en los casos estudiados en el último epígrafe, algunos de ellos recientes, mientras que parte de los Estados miembros del CEDH tienen en su agenda política el avance en el reconocimiento de derechos y la lucha contra la discriminación, otros van en dirección contraria, lo que confirma la necesidad de que organismos supranacionales, como el TEDH, actúen en defensa de los derechos de todas las personas.

\section{BIBLIOGRAFÍA}

Alonso García, Ricardo y Torres Muro, Ignacio, «La ley de derechos humanos (Human Rights Act 1998): una evolución a conciencia», Revista Española de Derecho Administrativo, núm. 105, 2000, pp. 5-36.

Álvarez RodríGuez, Ignacio, «La Organización de las Naciones Unidas y el derecho a la no discriminación por motivo de orientación sexual e identidad de género: apuntes para un debate», Revista General de Derecho Constitucional, núm. 17 (monográfico sobre El movimiento LGTB en perspectiva constitucional), 2013.

Arroyo GiL, Antonio, «De cómo por un mal camino se puede llegar a un buen sitio», Revista General de Derecho Constitucional, núm. 17 (monográfico sobre El movimiento LGTB en perspectiva constitucional), 2013.

Bouazza Ariño, Omar, «Tribunal Europeo de Derechos Humanos», Revista General de Derecho Administrativo, núm. 11, 2006.

— «Tribunal Europeo de Derechos Humanos», Revista General de Derecho Administrativo, núm. 14/2007.

Carmona Cuenca, Encarna, «La prohibición de discriminación. Nuevos contenidos. (Art. $14 \mathrm{CEDH}$ y Protocolo 12)», García Roca, Javier y Santolaya MachetTi, Pablo [Coords.]: La Europa de los Derechos. El Convenio Europeo de Derechos Humanos. Centro de Estudios Políticos y Constitucionales, Madrid, 2009, pp. 733-764.

Expósıтo, Enriqueta, «El derecho a contraer matrimonio entre personas del mismo sexo», Revista General de Derecho Constitucional, núm. 17 (monográfico sobre El movimiento LGTB en perspectiva constitucional), 2013. 
Frumer, Philippe, «La discrimination fondée sur l'orientation sexuelle dans les relations de partenariat ou de cohabitation: une question d'intérêt général devant la Cour Éuropéenne des Droits de l'Homme (l'arrêt Karner c. l'Autriche du 14 juillet 2003)», Revue trimestrielle des droits de l'homme, núm. 59, 2004, pp. 663-687.

García RocA, Francisco Javier, El margen de apreciación nacional en la interpretación del Convenio Europeo de Derechos Humanos: soberanía e integración. Civitas, Pamplona, 2010, pp. 91-92.

Gilbaja Cabrero, Estela, «Orientación sexual y filiación. Especial referencia a la adopción», Revista General de Derecho Constitucional, núm. 17 (monográfico sobre El movimiento LGTB en perspectiva constitucional), 2013.

Johnson, Paul, "'Homosexual propaganda' laws in the Russian Federation: are they in violation of the European Convention on Human Rights?» (bttp:// papers.ssrn.com/sol3/papers.cfm? abstract_id=2251005, consultado el 23/06/2014).

Kukura, Elizabeth, «Finding Family: Considering the Recognition of Same-Sex Families in International Human Rights Law and the European Court of Human Rights», Human Rights Brief 13, núm. 2, 2006, pp. 17-20.

MARGÉNAUd, Jean-Pierre, «Volte-face européenne sur le droit du célibataire homosexuel de pouvoir adopter». Revue trimestrielle de droit civil, abril-junio 2008, pp. 249-252.

MARTín SÁnCHEZ, María, «Aproximación histórica al tratamiento jurídico y social dado a la homosexualidad en Europa», Estudios Constitucionales (Centro de Estudios Constitucionales de Chile, Universidad de Talca), núm. 1, 2011, pp. 245-276.

— «El vago «sí» del Tribunal Constitucional», Revista General de Derecho Constitucional, núm. 17 (monográfico sobre El movimiento LGTB en perspectiva constitucional), 2013.

Matia Portilla, Francisco Javier, «Interpretación evolutiva de la Constitución y legitimidad del matrimonio formado por personas del mismo sexo», Teoría y Realidad Constitucional, núm. 31, 2013, pp. 535-554

Naranjo DE la Cruz, Rafael, «Matrimonio homosexual y categorías jurídicas», Revista General de Derecho Constitucional, núm. 17 (monográfico sobre El movimiento LGTB en perspectiva constitucional), 2013.

Rey MARTínez, Fernando, «Homosexualidad y Constitución», Revista Española de Derecho Constitucional, núm. 73, 2005, pp. 111-156.

Rodríguez YaGüE, Cristina, «Orientación sexual e identidad de género el proceso de consagración de derechos del colectivo LGTB», Revista General de Derecho Constitucional, núm. 15, 2012.

Ruiz-Risueño Montoya, Francisco M, «Los derechos de las personas LGBT en la jurisprudencia del Tribunal Europeo de Derechos Humanos», Revista General 
de Derecho Constitucional, núm. 17 (monográfico sobre El movimiento LGTB en perspectiva constitucional), 2013.

Salazar Benítez, Octavio, «El matrimonio igualitario como exigencia del libre desarrollo de la afectividad y sexualidad», Revista General de Derecho Constitucional, núm. 17 (monográfico sobre El movimiento LGTB en perspectiva constitucional), 2013.

Shabanova, Maria, «Rights of LGBT Minority in Russian Law and Practice», Russia and the EU Uneasy Relations. A Look From Belgium. Academic Papers of the 9th International Session of the HSE Russian - European Centre for Multidisciplinary Research, Brujas, 2009, pp. 190-195.

VAN Der Bogaert, Sina, «ECHR Rules on Illegal Ban of Warsaw Equality Parade: The Case of Baczkowski and Others v. Poland», German Law Journal, vol. 8, núm. 9, 2007, pp. 889-902.

Title:

SEXUAL ORIENTATION BEFORE THE EUROPEAN COURT OF HUMAN RIGHTS

\section{Summary:}

1. Introduction. 2. Sexual Orientation and Criminal Law: 2.1. Cases related to criminalization of homosexual relations. 2.2. Cases related to the age of consent for sexual relations. 3. Sexual Orientation and family life: 3.1. Marriage and other forms of legal recognition of stable same-sex couples. 3.2. Cases related to filiation. 4. Other relevant cases. 5. Conclusions. 6. Bibliography.

\section{Resumen:}

Este trabajo tiene por objeto el estudio de la jurisprudencia del TEDH en materia de orientación sexual, en la cual se basa el Tribunal Constitucional (STC 198/2012, de 6 de noviembre) para considerar la Constitución como un instrumento vivo que ha de interpretarse atendiendo a las condiciones presentes y, en consecuencia, decir que el art. 32.1 CE debe interpretarse de modo que no excluya el matrimonio entre personas del mismo sexo.

Para analizar la evolución de dicha jurisprudencia, he utilizado los documentos del TEDH en versión original (www.echr.coe.int) y con- 
sultado el Derecho interno relevante, así como bibliografía sobre el TEDH y los derechos LGTBI.

El texto se divide en seis apartados, incluyendo la introducción (primer epígrafe) y la bibliografía.

En el segundo epígrafe se comenta la jurisprudencia del TEDH sobre orientación sexual y Derecho Penal. El primer problema que analiza el Tribunal es la tipificación de las relaciones homosexuales en el Reino Unido, la República de Irlanda y Chipre. La prohibición fue declarada contraria al Convenio y las leyes modificadas. No obstante, algunos Estados mantuvieron la prohibición para los miembros del ejército y varias personas acudieron al Tribunal, que declaró violado el Convenio. Otro problema es el de la edad de consentimiento para las relaciones sexuales, en algunos países más elevada para las parejas del mismo sexo que para las de diferente; el Tribunal declaró esta distinción discriminatoria.

El objeto del tercer apartado es la jurisprudencia en materia de orientación sexual y vida familiar, comenzando con el matrimonio y otras formas de reconocimiento jurídico de las relaciones estables entre personas del mismo sexo y estudiando también asuntos relativos a la filiación. En estas Sentencias, la principal cuestión es si hubo violación de los arts. 8 y $14 \mathrm{CEDH}$. Puede apreciarse una evolución en las respuestas del Tribunal, según el cual el margen de apreciación de los Estados es aún importante pero los poderes públicos deben tener en cuenta que las diferencias basadas en el sexo o la orientación sexual requieren razones particularmente serias para justificarse. Dado que estos casos son muy recientes y hay algunos pendientes, no puede decirse que la opinión del TEDH en esta materia sea definitiva.

Se estudian también otros asuntos relevantes, en los que el TEDH analiza la eventual discriminación basada en la orientación sexual en relación con los arts. 3 (prohibición de la tortura y los tratos o penas inhumanos o degradantes), 10 (libertad de expresión) y 11 (libertad de reunión y asociación) del CEDH.

Las principales conclusiones alcanzadas al final del trabajo pueden resumirse así. En primer lugar, la tipificación de las relaciones homosexuales viola el derecho a la vida privada. Además, las diferencias basadas en la orientación sexual requieren razones especialmente serias para no ser discriminatorias. Por otro lado, el Tribunal declara que las parejas del mismo sexo necesitan, igual que las de distinto, reconocimiento y protección legales. Respecto a la filiación, se analiza cada caso concediendo a los Estados cierto margen de apreciación pero dentro de límites reducidos. 


\section{Abstract:}

The object of this work is to study the European Court of Human Rights case-law concerning sexual orientation, used by the Spanish Constitutional Court (STC 198/2012, 6 November) to consider the Constitution as a living instrument which has to be interpreted in present-day conditions and, consequently, say that Article 32.1 of the Constitution must be interpreted as not excluding same-sex marriage. To analyze the evolution of the mentioned case-law, I have used the official documents of the ECHR in their original version (www.echr. coe.int). In addition, I have consulted the relevant domestic Law when it has been necessary as well as some bibliography about ECHR and LGBTI rights.

The paper is divided into six sections, including introduction (first epigraph) and bibliography.

The second epigraph is about the ECHR case-law on sexual orientation and Criminal Law. The first problem analyzed by the Court is the criminalization of homosexual relations in the United Kingdom, the Republic of Ireland and Cyprus. The ban was found contrary to the Convention and laws were modified. However, certain of those States maintained the interdiction for the members of the army and several people went before the Court, who declared de Convention violated. Another problem in which Criminal Law is involved is that of the age of consent for sexual relations, which in some domestic Law is higher for same-sex couples than for different-sex ones; the Court found this distinction discriminatory.

The object of the third section is the ECHR case-law on sexual orientation and family life, starting with marriage and other forms of legal recognition of stable same-sex couples and also studying cases related to filiation. In this group of judgments, the main question answered by the Court is whether there has been a violation of Articles 8 and 14 of the Convention. An evolution can be seen in its responses, according to which the margin of appreciation of the States is still important, although public authorities have to take into account that differences based on sex or sexual orientation require particularly serious reasons by way of justification. As these cases are very recent and there are some pending, the opinion of the Court on this issue cannot be said to be definitive.

Afterwards, other relevant cases are studied, in which the ECHR analyzes the alleged discrimination based on sexual orientation in connection with Articles 3 (prohibition of torture and inhuman or degrading treatment or punishment), 10 (freedom of expression) and 11 (freedom of assembly and association) of the Convention. 
The main conclusions reached at the end of the work can be summarized as follows. First of all, criminalization of homosexual relations violates the right to respect for private life. In addition, differences based on sexual orientation need especially serious reasons not to be discriminatory. Moreover, the Court declares that same-sex couples need for legal recognition and protection as well as different-sex ones. As to filiation, the Court analyzes each case conferring the States certain margin of appreciation but within narrow limits.

\section{Palabras clave:}

Discriminación, homosexualidad, LGTBI, orientación sexual, TEDH.

Key words:

Discrimination, ECHR, homosexuality, LGBTI, sexual orientation. 